\title{
Multiple Structural Change Models: A Simulation Analysis*
}

\author{
Jushan $\mathrm{Bai}^{\dagger}$ \\ Picror Perron ${ }^{\ddagger}$ \\ Boston College. Boston University
}

This version: $\Lambda$ pril 3,2000

\begin{abstract}
In a recent paper. Bai and Perron (1998) considered theoretical issues related to the limiting distribution of estimators and test statistics in the linear model with multiple structural changes. We assess. via simulations, the adequacy of the various methods suggested. These cover the size and power of tests for structural changes, the coverage rates of the confidence intervals for the break dates and the relative merits of methods to select the number of breaks. The various data generating processes considered allow for general conditions on the data and the errors including differences across segments. Various practical recommendations are made.
\end{abstract}

JEL Classification Number: C20.

Keywords: change-point, segrnented regressions, break dat es. hypothesis testing. model selection.

"Jushan Bai acknowledges financial support from the National Science Foundation under Grant SBR970950S. Address for correspondence: Pierre Perron, Department of Economics. Boston University: 270 Bay State Road. Brston. 02215, USA (e-mail: perron@bu.edu).

${ }^{\dagger}$ Department of Economics, Boston College. Chestnut Hill, MA, 0246i (jushan.baigibc.edu).

${ }^{\ddagger}$ Department of Economics. Boston University; 270 Bay State Rd., Boston. MA. 02215 (perron'âluu.edu). 


\section{Introduction.}

Broth the statistics and romometrics literature contain a vast anoment of work on issues related to stouctural change, most of it specifically designed for the case of a single change. Hewerer, the problem of mult iple structural changes has reneived considerably less at tenttion. Rerently; Bai and Perron (1998, 1999) provided a comprehensive treatment of majous issines in the contest of multiple structural change models: consistency of estimales of the lomak dates, tests for structural changes, confidener intervals for the hreak dates, methorls tor select the number of breaks and efficient algorithms to compute the estimates. Howerer. their results are solely asymptotic in nature and the adefuacy in finite samples rematins lo be incestigater. In this paper, we intend ton partially fill this gatp.

Ire present. sinnulation results pertaining to the behavion of the estinators and teste in finite samples. We consider the problem of forming confidence interwals for the breale dates under varions hypotheses about the structure of the data and errors across segments. In particular. we may allow the data and errors to have different distributions across segments or impose a common structure. The issue of testing for structural changes is also considered under very general conditions on the dat a and the errors and the propertics of tests, both in the data-genemating processes and in the specification of the tests. Wo also address the issine of estimat ing the number of breaks. To that effect, we discuss methods based on informatinn criteria and a method based on a sequential testing procedure as suggested in Bai and Perron (1998).

The rest of this paper is structured as follows. Section 2 presents the model and the estimator. Section 3 summarizes the relevant asymptotic results about the construction of confidence intervals for the break dates, the tests for multiple structural changes and methods to estimate the number of breaks. It describes the exact nature of the various tests and procedures upon various specifications about the nature of the crrors and dati across segments. Section 4 presents the results of simulations analyzing the adequacy of the asymptotic approximations in finite samples, the size and power of the various tests and the relative merits of scveral methods to estimate the number of structural changes. Some concluding remarks and practical recommendations are contained in Section 5. 


\section{The Model and Estimators.}

For the purpose of the simulation study, we consider the following multiple linear regression with m hroks ( $m+1$ regimes):

$$
y_{t}=z_{t}^{\prime} \delta_{j}+u_{t}: \quad t=T_{j-1}+1 \ldots . T_{3}
$$

for $j=1 \ldots . . m+1$. This is a special case of the general nurdel considered in Bai and Perron (1998) corresponding to a pure structural change nodel. Here, $y /$ is the obsered depentent variahle at time $t ; \Rightarrow(q \times 1)$ is a vectors of covariates and $\delta_{j}(j=1, \ldots, m+1)$ is the corresponding vector of coeflicients; $u_{t}$ is the disturbance at time $t$. The indices $\left(T_{1} \ldots . . T_{m}\right)$, or the brak points, are explicity treated as unknown (wo use the convention that $T_{0}=0$ and $T_{m+1}=T$ ). The purpose is to estimate the unknown regression coefficients together with the break points when $T$ observations on $\left(y_{l}, z_{l}\right)$ are available.

The method of estimation considered is that based on the least-scfuares principle. For $=$ each $m$-partition $\left(T_{1} \ldots . T_{m}\right)$; the associated least-squares estimates of $\delta_{j}$ are obtaincd by minimizing the sum of squared residuals

$$
S_{T}\left(T_{1} \ldots, T_{m}\right)=\sum_{i=1}^{m+1} \sum_{t=T_{i-1}+1}^{T_{i}}\left[y_{t}-z_{t}^{\prime} \delta_{i}\right]^{2} .
$$

Let $\dot{\varepsilon}\left(\left\{T_{j}\right\}\right)$ denote the resulting estimates br.sed on the given m-partition $\left(T_{1}, \ldots . T_{m}\right)$ denoted $\left\{T_{j}\right\}$. Substituting these estimates in the objective function, the estimated break points $\left(\dot{T}_{1} \ldots . . \dot{T}_{m}\right)$ are such that

$$
\left(\hat{T}_{1}, \ldots, \hat{T}_{m}\right)=\operatorname{argmin}{ }^{T_{1}}, \ldots, T_{m} S_{T}\left(T_{1}, \ldots, T_{m}\right),
$$

where the minimization is taken over all partitions $\left(T_{1}, \ldots, T_{m}\right)$ such that $T_{i}-T_{i-1} \geq h \geq q$. Thus the break-point estimators are global minimizers of the objective function. Finally, the regression parameter estimates are obtained using the associated least-squares estimates at the estimated $m$-partition $\left\{\hat{T}_{j}\right\}$, i.e. $\delta=\hat{\delta}\left(\left\{\hat{T}_{j}\right\}\right)$. An efficient algorithm, based on the principle of dynamic programming, to obtain global minimizers of the sum of squared residuals is presented in Bai and Perron (1999).

Note that, in general, $h$ need not be set to $q$. Indeed, in many instances the choice of the trimming is made independently of the number of regressors. This is the case, in particular when obtaining estimates for the purpose of constructing test statistics (sce Section 3.2 helow 
A contral result derived in Bait and Perron (1908) concerus the convergence of the hreat:

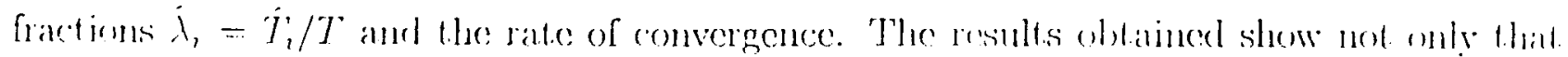
$\lambda$, conrerges to its true value $\lambda_{2}^{0}$ but that it, does so at the fast wat.e $T$. i.c. $T\left(\lambda_{2}-\lambda_{2}^{\prime \prime}\right)=$

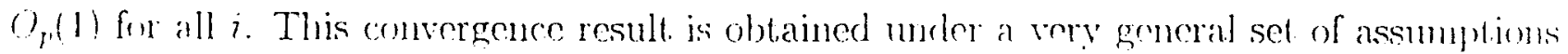

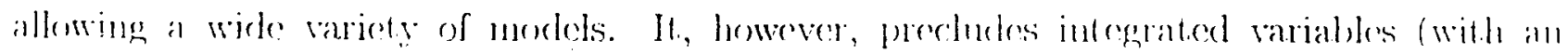

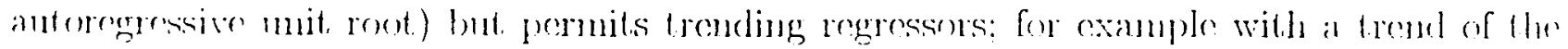
form $g_{t}=a+b(t / T)$. The assumptions conceming the nature of the crrors in relation ton the renressers $\left\{z_{t}\right\}$ are of two kinds. First, when no lagged dependent variable is allowed in $\{a\}$. the ronditions on the residuals are guito general and allow substantial correlation and heteroskedasticity. The second case allows lagged dependent variables as regressoms but.

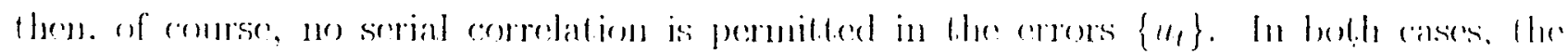
assumptions are general enough to allow different distributions for both the regressors and the errors across segments.

\section{$=3$ Summary of Relevant Asymptotic Results.}

\subsection{Constructing Confidence Intervals.}

To get an asymptotic distribution for the break dates, the strategy considered is to adopt an asympt of ic framework where the magnitudes of the shifts converge to zero as the sample size increases. The resulting limiting distribution is then independent of the specific distribution of the pair $\left\{z_{t}, u_{t}\right\}$. To describe the relevant distributional result, we need to define some notations. For $i=1 \ldots . m$. and $\Delta T_{i}^{0}=T_{i}^{0}-T_{i-1}^{0}$, let

$$
\begin{aligned}
& \Delta_{i}=\delta_{i+1}^{0}-\delta_{i}^{0}, \\
& Q_{i}=\lim \left(\Delta T_{i}^{0}\right)^{-1} \sum_{t=T_{i-1}^{0}+1}^{T_{i}^{0}} E\left(z_{i} z_{t}^{\prime}\right) . \\
& \Omega_{i}=\lim \left(\Delta T_{i}^{0}\right)^{-1} \sum_{r=T_{i-1}^{0}+1}^{T_{i}^{0}} \sum_{t=T_{i-1}^{0}+1}^{T_{i}^{0}} E\left(z_{r} z_{t}^{\prime} u_{r} u_{t}\right) .
\end{aligned}
$$

In the case where the data are non-trending, we have, under various assumptions ${ }^{1}$ stated in

\footnotetext{
'The important ones are as follows: the magnitude of the shifts decreases at a suitable rate as the sample size increases, a functional central limit theorem holds for the partial sums of the variables $\left\{z_{t} u_{t}\right\}$. also $p \lim \left(\Delta T_{i}^{0}\right)^{-1} \sum_{t=T_{t-1}^{\prime}+1}^{T_{t-1}^{0}+\left\{\Delta T_{i}^{n} \mid\right.} E\left(z_{t} z_{t}^{\prime}\right)=s Q_{i}$ is assumed to exist with $Q_{i}$ a fixed matrix. The latter precludrs trending regressors.
} 
Bai and Perron (1998), the following limiting distribution of the lureak dates:

$$
\frac{\left(\Delta_{i}^{\prime}\left(Q_{2} \Delta_{i}\right)^{2}\right.}{\left(\Delta_{i}^{\prime} \Omega_{1} \Delta_{i}\right)}\left(\hat{T}_{i}-T_{i}^{0}\right) \Rightarrow \arg \max _{s} T^{\prime \prime \prime}(s) . \quad(i=1, \ldots m)
$$

where

$$
V^{-n)}(s)= \begin{cases}W_{1}^{(i)}(-s)-|. s| / 2 . & \text { if } s \leq 0 . \\ \sqrt{\xi_{1}}\left(\sigma_{1,2} / \sigma_{1,1}\right) W_{2}^{-(i)}(s)-\xi_{1}|.| s \mid / 2 . & \text { if } s>0 .\end{cases}
$$

and

$$
\begin{aligned}
\xi_{i} & =\Delta_{i}^{\prime} Q_{i+1} \Delta_{i} / \Delta_{i}^{\prime} Q_{i} \Delta_{i}, \\
d_{i, 1}^{\prime} & =\Delta_{i}^{\prime} \Omega_{i} \Delta_{i} / \Delta_{i}^{\prime} Q_{i} \Delta_{i} . \\
\theta_{i, 2}^{2} & =\Delta_{i}^{\prime} \Omega_{i+1} \Delta_{i} / \Delta_{i}^{\prime} Q_{i+1} \Delta_{i} .
\end{aligned}
$$

Also. $W_{1}^{-i n}(s)$ and $W_{2}^{-(i)}(s)$ are independent standard Weiner proresses defined on $[0 . \propto)$. starting at the origin when $s=0$. These processes are also independent across $i$.

The cumulative distribution function of $\operatorname{argmax}_{s} V^{(i)}(s)$ is derived in Bai (1997a) ancl all $=$ that is needed to compute the relevant critical values are estimates of $\Delta_{i}, Q_{n}$, and $\Omega_{i}$. These are given by-

$$
\begin{aligned}
& \hat{\Delta}_{i}=\hat{\delta}_{i+1}-\hat{\delta}_{i} . \\
& \hat{Q}_{i}=\left(\Delta \hat{T}_{i}\right)^{-1} \sum_{t=\hat{T}_{i-1}+1}^{\hat{T}_{1}} z_{t} z_{t}^{\prime} .
\end{aligned}
$$

and an estimate of $\Omega$, can be constructed using the covariance matrix estimator of Andrew's (1991) applied to the vector $\left\{z_{t} \hat{u}_{t}\right\}$ and using data over segment $i$ only: We use the Quadratic Spectral kernel with an AR(1) approximation for each element of the vector $\left\{\tilde{z}_{\hat{u}} \hat{u}_{\ell}\right\}$ to construct the optimal bandwidth (henceforth referred to as a HAC estimator).

In practice, one may want to impose some constraints on this general framework related to the distribution of the errors and regressors across segments. For ease of reference, especially with the simulation results presented later, we shall adopt the following notation. We denotc by cor_ $u=1$ the case where the crrors are allowed to be correlated and by cor_ $u=0$ the case where no correction for serial correlation is made. Similarly, het $z=1$ denotes the case where the regressors are allowed to have heterogenous distributions across segments and by het_z $z=0$ the case where the distributions are assumed to be homogenous across segments. Finally: het_u=1 permits heterogenous variances of the residuals across scgments and het_u $=0$ imposes the same variance throughout. We have the following cases when adding restrictions: 
- The regressors z are identically distributed across segments (cor_ $u=1$, het $z=0$ ). hert_" =1). Then $Q_{i}=Q_{i+1}=Q$ which can consistently be estimated by $Q_{i}=$ $T^{-1} \sum_{t=1}^{T} z_{1} z_{t}^{\prime}$. In this case, the liniting result states that.

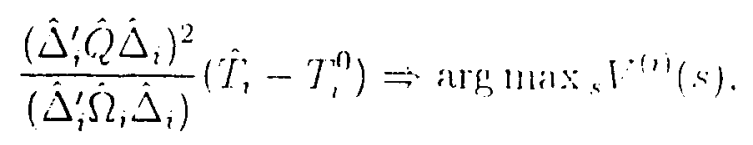

$w i t h \xi_{1}=1$.

- The errors are identically distributed across segments (con_z ${ }^{\prime}=1$, het $z=1$. het ${ }^{\prime \prime}=$ 0). Then $\Omega_{1}=\Omega_{1+1}=\Omega$ which can consistently be estimated using a HAC (stimatum applied to the variable $\{z \hat{u}$,$\} , using data orer the whole samble.$

- The errors and the data are identically distributed across segments (cor $u=1$. hot_z=0. het_u=0). Here, we have $\xi_{i}=1$, and $\phi_{i, 1}=\phi_{i, 2}$ and the limiting distribution reduces to

$$
\frac{\left(\hat{\Delta}_{i}^{\prime} \hat{Q} \hat{\Delta}_{i}\right)^{2}}{\left(\hat{\Delta}_{i}^{\prime} \hat{\Omega} \hat{\Delta}_{i}\right)}\left(\hat{T}_{i}-T_{i}^{(0)} \Rightarrow \arg \max _{s}\left\{\Pi^{-(i)}(s)-|s| / 2\right\}\right.
$$

which lias a density function symmetric about the origin.

- The crrors are serially uncorrelated (cor_ $u=0$, het_z $z=1$, het_u=1). In this casc $\Omega_{i}=\sigma_{i}^{2} Q_{i}$ and $\delta_{i, 1}^{2}=\dot{\phi}_{i .2}^{2}=\sigma_{i}^{2}$ which can be estimated using $\hat{\sigma}_{i}^{2}=\left(\Delta \hat{T}_{i}\right)^{-1} \sum_{t=T_{i-1}+1}^{\hat{T}_{i}} \hat{u}_{i}^{2}$. The confidence intervals can then be constructed from the approxination

$$
\frac{\left(\hat{\Delta}_{i}^{\prime} \hat{Q}_{i} \hat{\Delta}_{i}\right)}{\hat{\sigma}_{i}^{2}}\left(\hat{T}_{i}-T_{i}^{0}\right) \Rightarrow \arg \max _{s} V^{(i)}(s)
$$

- The crrors are serially uncorrelated and the regressors are identically distributed across segments (cor_ $u=0$, het_z $z=0$, het_u=1). Here $\phi_{i, 1}^{2}=\phi_{i, 2}^{2}=\sigma_{i}^{2}$ and $\xi_{i}=1$. The confidence intervals can then be constructed from the approximation

$$
\frac{\left(\hat{\Delta}_{i}^{\prime} \hat{Q} \hat{\Delta}_{i}\right)}{\hat{\sigma}_{i}^{2}}\left(\hat{T}_{i}-T_{i}^{0}\right) \Rightarrow \arg \max _{s}\left\{W^{(i)}(s)-|s| / 2\right\}
$$

- The errors are serially uncorrelated and identically distributed across segments (cor_ $u=$ 0. het_z $z=1$, het_u=0). The approximation is the same as (5) with $\hat{\sigma}^{2}=T^{-1} \sum_{t=1}^{T} u_{t}^{2}$ instead of $\dot{\sigma}_{i}^{2}$. 
- The errors are serially uncorrelated and both the datid and the crrors are irlentically dist ributed across segmonts $\left(\right.$ cor_u $u=0$, het $t_{-} z=0$. het_ $\left.u=0\right)$. The approximat ion is the same as (6) with $\hat{\sigma}^{2}$ instead of $\hat{\sigma}_{i}^{2}$.

Sine the break dates are integer valued, we consider ennfidence intervals that are likewise integratalued be using the highest smaller integer for the bewer bound and the smallest ligaler integer for the upper boums.

\subsection{Test Statistics for Multiple Breaks.}

\subsubsection{A Test of no breok versus a fixed number of loreaks.}

IV. consiste the sup F type test, of no structural break $(m=0)$ insus the alternation hrpothesis that there are $m=k$ breaks. Let $\left(T_{1} \ldots . T_{k}\right)$ be a partition such that $T_{i}=\left[T_{\lambda} \lambda_{i}\right]$ $(i=1 \ldots . . k i)$. Let $R$ be the conventional matrix such that. $(R \delta)^{\prime}=\left(\delta_{1}^{\prime}-\delta_{2}^{\prime} \ldots . \delta_{k}^{\prime}-\delta_{k:-1}^{\prime}\right)$. Drfine

$$
F_{T}^{*}\left(\lambda_{1} \ldots, \lambda_{k}: q\right)=\frac{1}{T}\left(\frac{T-(k+1) q}{k q}\right) \hat{\delta}^{\prime} R^{\prime}\left(R \hat{V}(\hat{\delta}) R^{\prime}\right)^{-1} R \hat{\delta}
$$

where $i(\hat{\delta})$ is an estimate of the variance covariance matrix of $\hat{\delta}$ that is robust to serial correlation and heteroskedasticity; i.e. a consistent estimate of

$$
V(\hat{\delta})=p \lim T\left(\bar{Z}^{\prime} \bar{Z}\right)^{-1} \bar{Z}^{\prime} \Omega \bar{Z}\left(\bar{Z}^{\prime} \bar{Z}\right)^{-1}
$$

The statistic $F_{T}^{*}$ is simply the conventional $F$-statistic for testing $\delta_{1}=\cdots=\delta_{k+1}$ against $\delta_{1} \neq \delta_{i+1}$ for some $i$ given the partition $\left(T_{1} \ldots, T_{k}\right)$. The supF type test statistic is then defined as

$$
\operatorname{supF}_{T}^{*}(k ; q)=\sup _{\left(\lambda_{1} \ldots, \ldots \lambda_{k}\right) \in \Lambda_{c}} F_{T}^{*}\left(\lambda_{1} \ldots, \lambda_{k} ; q\right)
$$

where

$$
\Lambda_{\epsilon}=\left\{\left(\lambda_{1}, \ldots, \lambda_{k}\right) ;\left|\lambda_{i+1}-\lambda_{i}\right| \geq \epsilon, \lambda_{1} \geq \epsilon, \lambda_{k} \leq 1-\epsilon\right\},
$$

for some arbitrary positive number $\epsilon$. In this general case, allowing for serial correlation in the errors. the supF $F_{T}^{*}(k ; q)$ may be rather cumbersome to compute. However, one can obtain a much simpler, yet asymptotically equivalent, version by using the estimates of the break dates obtained from the global minimization of the sum of squared residuals. Denote, thesi estimates by $\dot{\lambda}_{i}=\dot{T}_{i} / T$ for $i=1, \ldots, k$, the test is then

$$
\sup _{T}(k ; q)=F_{T}^{*}\left(\hat{\lambda}_{1}, \ldots, \hat{\lambda}_{k}: q\right)
$$


The estimates $\hat{\lambda}_{1} \ldots, \hat{\lambda}_{k}$ are equivalently the arguments that maximizes the following $F$ statistir:

$$
F_{T}\left(\lambda_{1}, \ldots, \lambda_{k} ; q\right)=\left(\frac{T-(k+1) q}{k q}\right) \dot{\delta}^{\prime} R^{\prime}\left(R \hat{V}(\dot{\delta}) R^{\prime}\right)^{-1} R \hat{\delta}
$$

anrl

$$
\widetilde{V}(\delta)=\left(\frac{\bar{Z}^{\prime} \bar{Z}}{T}\right)^{-1}
$$

the wantanere matrix of $\dot{\delta}$ assuming spherical crors. This procedure is asymutentically. rquimalent since the break dates are consistent even in the presence of serial correlation. The assmputertic distribution still depends on the specification of the set $\Lambda_{c}$ via the imposition of the minimal length $h$ of a segment. Hence, $c=h / T$.

Varions versions of the tests can be obtained depending on the assumptions mate with respect to the distribution of the data and the errors across segments. These variations relates to different specifications in the construction of the estimate of the liniting covariance matrix $V(\bar{s})$ giron by (8). They are the following.

- No serial corrolation. different distributions for the data and identical distribution for the crrors across segments (cor_ $u=0$. het $z=1$. het_ $u=0$ ). In this base case. the estimate is

$$
\hat{V}(\dot{\delta})=\hat{\sigma}^{2}\left(\frac{\bar{Z}^{\prime} \bar{Z}}{T}\right)^{-1}
$$

- No serial correlation in the errors, different variances of the errors and different distributions of the data across segments $\left(c_{-} u=0\right.$. het $z=1$, het $\left.u=1\right)$. In this case.

$$
\hat{V}(\hat{\delta})=\operatorname{diag}\left(\hat{V}\left(\hat{\delta}_{1}\right), \ldots, \hat{V}\left(\hat{\delta}_{m+1}\right)\right)
$$

where $\hat{V}\left(\hat{\delta}_{i}\right)$ is the covariance matrix of the estimate $\hat{\delta}_{i}$ using only data from segment i. i.e. $\left.\hat{V}\left(\dot{\delta}_{i}\right)=\hat{\sigma}_{i}^{2} l\left(\Delta \hat{T}_{i}\right)^{-1} \sum_{t=\hat{T}_{i-1}+1}^{\dot{T}_{i}} z_{t} z_{t}^{\prime}\right]^{-1}$ with $\hat{\sigma}_{i}^{2}=\left(\Delta \hat{T}_{i}\right)^{-1} \sum_{t=\hat{T}_{t-1}+1}^{\hat{T}_{i}} \hat{u}_{i}^{2}$. These arc simply the $O L S$ estimates obtained using data from each segment separately.

- Serial correlation in the errors, different distributions for the data and the errors across segments (cor_u $=1$, het_ $z=1$, het_u=1). Here, we make use of the fact that the errors in different segments are asymptotically independent. Hence, the limiting variance is given by

$$
V(\hat{\delta})=\operatorname{diag}\left(V\left(\hat{\delta}_{1}\right), \ldots, V\left(\hat{\delta}_{m+1}\right)\right)
$$


wher. for $i=1 \ldots . m+1$.

$$
V\left(\hat{\delta}_{i}\right)=p \lim \left(\Delta T_{i}\right)\left(Z_{i}^{\prime} Z_{i}\right)^{-1} Z_{i}^{\prime}\left(\Omega_{i} Z_{i}\left(Z_{i}^{\prime} Z_{2}\right)^{-1}\right.
$$

This an be consistently estimated, segment by segnent, with a HAC estimaton of $v\left(\dot{r}_{,}\right)$using only data from segment. $i$.

- Srrial correlation in the errors, same distribution for the errors across segments $\left(\mathrm{crm}_{-} u=\right.$ 1. het_z $z=1$. het_ $u=0$ ). In this case the limiting covariance matrix is

$$
V(\delta)=p \lim T\left(\bar{Z}^{\prime} \bar{Z}\right)^{-1}\left(\Lambda \curvearrowright\left(Z^{\prime} \Omega Z\right)\right)\left(\bar{Z}^{\prime} \bar{Z}\right)^{-1}
$$

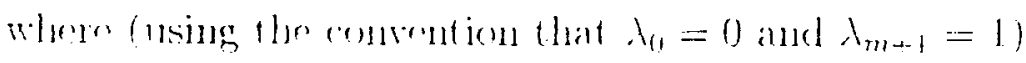

$$
\Lambda=\left(\begin{array}{cccc}
\lambda_{1}-\lambda_{0} & & & \\
& \lambda_{2}-\lambda_{1} & \\
& & \ddots & \\
& & & \lambda_{m+1}-\lambda_{m}
\end{array}\right) .
$$

This can be consistently estimated using $\hat{\lambda}_{i}=\hat{T}_{1} / T$ and a HAC estimator based on the pair $\left\{\tilde{z}_{t} \dot{u}_{t}\right\}$ constructed using the full sample. Note that we have an implicit assumption that the regressors $z$ l have the same distribution across segments since the consistent estimate of $p \lim Z^{\prime} \Omega Z / T$ is constructed using the full sample. For reasons, discussed below we do not impose that restriction when evaluating $p \lim \bar{Z}^{\prime} \bar{Z} / T$. That is, we still use $\bar{Z}^{\prime} \bar{Z} / T$ instead of an estimate of $(\Delta \Xi Q)$ obtained using $\bar{Q}=T^{-1} \sum_{t=1}^{T} z_{1} z_{t}^{\prime}$ based on the full sample.

In the construction of the tests we do not consider imposing the restriction that the distribution of the regressors $z_{t}$ be the same across segments even if they are (except as they enter in the construction of a HAC estimate involving the pair $\left\{z_{t} \hat{u}_{t}\right\}$ ). This might at first sight scem surprising since imposing a valid restriction should lead to more precise estimate. This is, howerer, not truc. Consider the case with no serial correlation in the errors and the same distribution for the errors across segments (cor_ $u=0$, het_ $u=0$ ). Imposing the restriction het $z=0$, leads to the following asymptotic covariance matrix

$$
V(\hat{\delta})=\sigma^{2}(\Lambda \ominus Q)^{-1}
$$


where $Q=\lim _{T \rightarrow x} T^{-1} \sum_{t=1}^{T} E\left(z_{t} z_{t}^{\prime}\right)$. Note that a consistent rstimate (an be obtained using

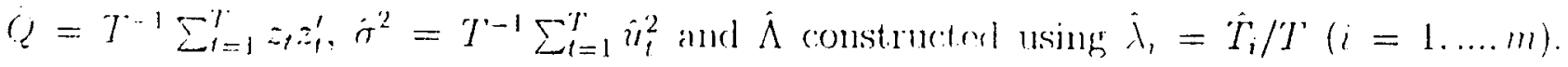

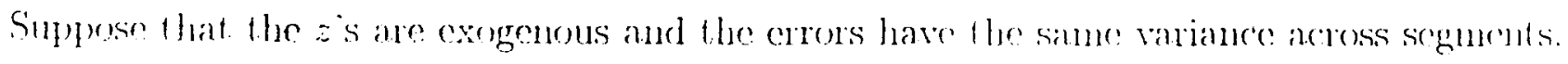

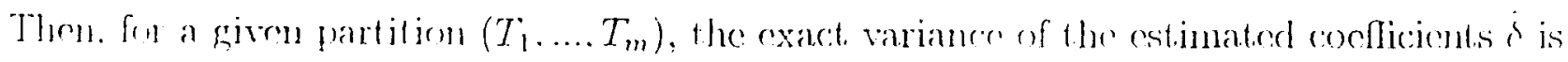

$$
V(\delta)=\sigma^{2}\left(\frac{\bar{Z}^{\prime} \bar{Z}}{T^{\prime}}\right)^{-1}
$$

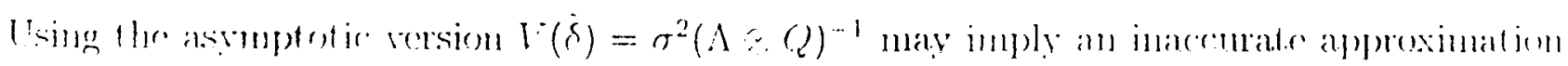

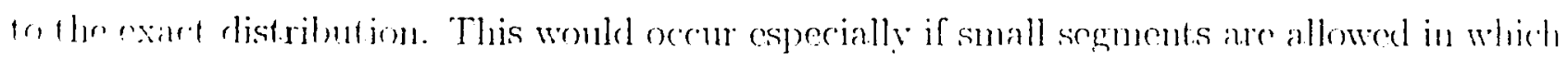
ast the raget moment matrix of the regressors may deviate substantially from its full sammph analug

The sane problem occurs in the case with no serial correlation in the crrors and different

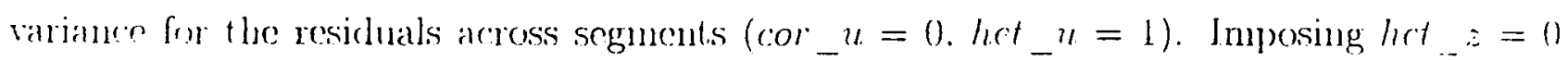
gives the limiting variance

$$
V(\hat{\delta})=\left(\Lambda^{*} \delta Q\right)^{-1}
$$

whore

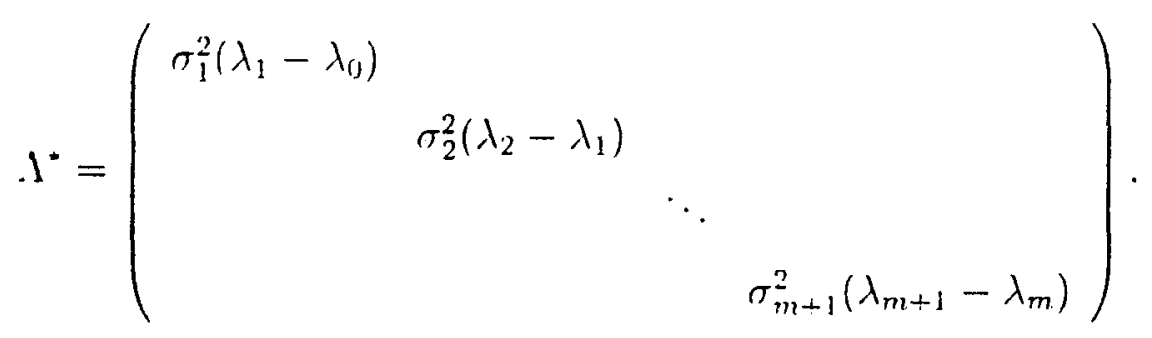

which can be consistently estimated using $\hat{Q}, \hat{\lambda}_{i}=\hat{T}_{i} / T$ and $\hat{\sigma}_{i}^{2}=\left(\Delta \hat{T}_{i}\right)^{-1} \sum_{t=j_{i-1}+1}^{\hat{T}_{i}}$. Again. in finite samples, imposing the constraint, that $Z_{i}^{\prime} Z_{i} /\left(\Delta \hat{T}_{i}\right)$ be approximated by $\dot{Q}$ over all segments may imply a poor approximation in finite samples. We have found, in these twr) cascs, that imposing a common distribution for the regressors across scgmcnts leads to tests with worse properties even when the data indeed have an invariant distribution. These distortions becomes less important, however, when the sample size is large and/or the trimming $\epsilon$ is large.

The relevant asymptotic distribution has been derived in Bai and Perron (1998) and critical values can be found in Bai and Perron (1998) for a trimming $\epsilon=.05$ and values of $k$ from 1 to 9 and values of $q$ from 1 to 10 . As the simulation experiments will show, a trimming as small as $5 \%$ of the total sample can lead to tests with substantial size distortions when allowing different variances of the errors across segments or when serial correlation is pemitted. This is because one is then trying to estimate various quantities using very few 
ohservations: for example, if $T=100$ and $c=.05$, one culs up estimat.jng, for some segments. quantities like the variance of the residuals using only 5 observations. Similarly, with serial correlation a IIAC estimator would need to be applied to very short samples. The estiniates ane then highly imprecise and the tests accordingly show size distortions. When allewing difforent varianens across segments or serial correlation a higher walue of $e$ should he userl.

Henere. the rase (cor_ $u=0$. het_z $z=1$, het_ $u=0)$ shomld be considered the hase wise in which the tests can be constructed using an arbitatry small trimning r. For all othere cascs.s care should be exercised in the choice of e and larger malues should be considered. Citical malues for trimming paraneter $\epsilon=.10, .15,20$ and 25 (an be found in Bai and Pen ron (1999). Note that whene $e=.10$ the maximum number of break considered is 8 since

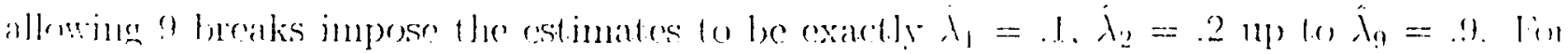
smilar rasons, the maximum number of breaks allower is 5 when $c=.15 .3$ whon $c=.20$ and 2 when $c=.25$.

\section{$=3.2 .2$ Double maximum tests.}

Oftcn. an inrestigator wishes not to pre-specify a particular number of breaks to make inference. To allow this Bai and Perron (1998) have introduced two tests of the null hypothesis of no structural break against an unknown number of breaks given some upper bound $M$. These are called the double maximum tests. The first is an equal weighted version defincel by

$$
\text { LiD max } F_{T}^{*}(M, q)=\max _{1 \leq n \leq \leq M} \sup _{\left(\lambda_{1}, \ldots, \lambda_{m}\right) \in \lambda,} F_{T}^{*}\left(\lambda_{1} \ldots \ldots \lambda_{m} ; q\right) .
$$

We use the asmonptotically equivalent version

$$
U D \max F_{T}(M . q)=\max _{1 \leq m \leq M} F_{T}\left(\hat{\lambda}_{1}, \ldots, \hat{\lambda}_{m} ; q\right)
$$

where $\hat{\lambda}_{j}=\hat{T}_{j} / T(j=1, \ldots m)$ are the estimates of the break points obtained using the global minimization of the sum of squared residuals.

The second test applies weights to the individuals tests such that the marginal p-ralues are equal across values of $m$. This implies weights that depend on $q$ and the significance level of the test, say $a$. To be more precisc, let $c(q, a, m)$ be the asymptotic critical ralue of the test $\sup _{\left(\lambda_{1}, \ldots, \lambda_{m}\right) \in \Lambda,} F_{T}\left(\lambda_{1}, \ldots, \lambda_{m} ; q\right)$ for a significance level $a$. The weights are then defined as $a_{1}=1$ and for $m>1$ as $a_{m}=c(q, a, 1) / c(q, a, m)$. This version is denoted

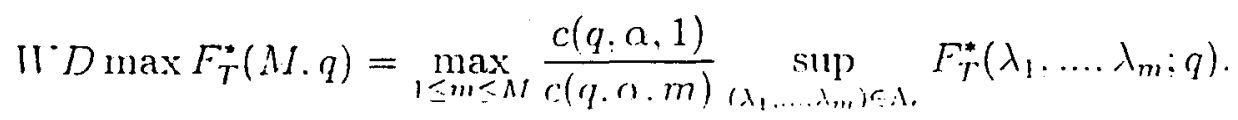


Again. wo use the asymptotically equivalent version

$$
W D \max F_{T}(M, q)=\max _{1 \leq m \leq M} \frac{c(q \cdot \alpha, 1)}{c(q \cdot \alpha \cdot m)} F_{T}\left(\hat{\lambda}_{1}, \ldots, \hat{\lambda}_{m}: q\right)
$$

Note that, unlike the UD max $F_{T}(M, q)$ test, the value of the $T^{-} D$ max $F_{7}(M . q)$ depents on the significance level chosen since the weights themselves depend on a. Critical values can be found in Dai and Porron $(1998,1999)$ for $r=.95)(M=5), r=.10(M=5), .15$ $(M=5), .20(M=3)$ and $.25(M=2)$.

\subsubsection{A test of $\int$ versus $(+1$ breaks.}

Bai and Perren (1998) proposed a test. For ( versus $(+1$ braks. This test is labetherl

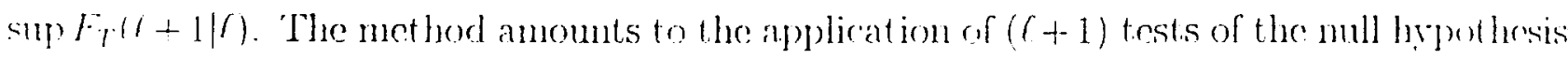
of no structural change versus the altcmative hypothesis of a single change. The test is applied to each segment containing the observations $\hat{T}_{i-1}$ to $\hat{T}_{i}(i=1 \ldots \ldots+1)$. The estimatios $=\dot{T}_{\text {, need }}$ not be the global minimizers of the sum of squared residuals, all that is recunired is that the break fractions $\hat{\lambda}_{i}=\hat{T}_{i} / T$ comerge to their true value at rate $T$. We conclude for a rejection in favor of a model with $(\ell+1)$ breaks if the overall minimal value of the sum of squared residuals (over all segments where an additional break is included) is sufficiently smaller than the sum of squared residuals from the $\ell$ breaks model. The break date thus selected is the one associated with this overall minimum.

Asymptotic critical values were provided by Bai and Perron $(1998,1999)$ for $q$ ranging from 1 to 10. and for trimming values $\varepsilon$ of $.05, .10, .15, .20$ and .25 . Of course, all the same options are arailable as for the previous tests concerning the potential specifications of the nat.ure of the distributions for the errors and the data across segments.

\subsection{Estimating the number of breaks.}

A common procedure to select the dimension of a model is to consider an information criterion. Yao (1988) suggests the use of the Bayesian Information Criterion $(B I C)$ defined as

$$
B I C(m)=\ln \hat{\sigma}^{2}(m)+p^{*} \ln (T) / T,
$$

where $p^{*}=(m+1) q+m+p$, and $\hat{\sigma}^{2}(m)=T^{-1} S_{T}\left(\hat{T}_{1}, \ldots, \hat{T}_{m}\right)$. He showed that the number of breaks can be consistently estimated (at least for normal sequence of random variables with shifts in mean). An alternative proposed by Liu, Wu and Zidek (1994) is a modified 
Simwar eriterion that takes the form:

$$
L \Pi Z Z(m)=\ln \left(S_{T}\left(\hat{T}_{1} \ldots . \dot{T}_{m}\right) /\left(T-p^{*}\right)\right)+\left(p^{*} / T\right) C_{n}(\ln (T))^{2+\delta_{n}}
$$

Ther suggest using $\delta_{0}=0.1$ and $c_{0}=0.299$. Perron (1997) presnuted a simulation study uf

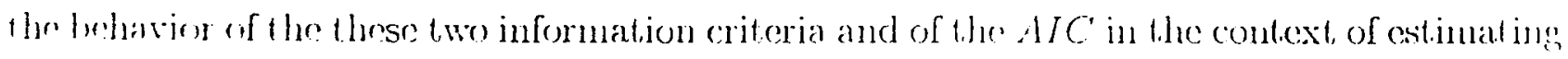
the munber of changes in the trend function of a series in the presence of scrial correlation. The results first showed the $A I C$ to perform very hadly and, henec, this critorion will unt

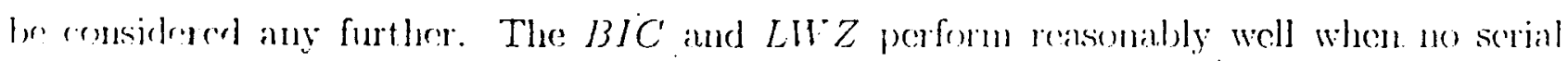
correlation in the erross is present but imply choosing a mmber of breaks much higher than the true value when serial corrclation is present. When no serial correlation is present in the mores but a lageged dependent variable is present. the $B J C^{2}$ performs barly when the renfleient on the lagged dependent variable is large (and more so as it approaches mity). In such cases. the $L H^{\circ} Z$ performs better under the null of no break but underestimate the number of broaks when some are present.

The method suggested by Bai and Perron (1998) is based on the sequential application of the sup $F_{Y}(\tau+1 \mid r)$ test. The procedure to estimate the number of breaks is the following. Start by estimating a model with a small number of breaks that are thought to be necessary. (or start mith no break). Then perform parameter-constancy tests for each subsamples (those obtained by cutting off at the estimated breaks), adding a break to a subsample associated with a rejection with the test $\sup F_{T}(\ell+1 \mid \ell)$. This process is repeated increasing $\ell$ sequentially until the test $\sup F_{T}(\ell+1 \mid \ell)$ fails to reject the null hypothesis of no additional structural changes. The limiting distribution of the test is the same when using global minimizcrs for the estimates of the break dates or sequential one-at-a-time estimates since both imply lreak fractions that converge at rate $T$ (see Bai (1997b)). The final number of breaks is thus equal to the number of rejections obtained with the parameter constancy tests plus the number of breaks used in the initial round.

A distinct advantage of model selection procedures based on hypothesis testing is that, unlike information criteria, they can directly take into account the possible presence of serial correlation in the errors and non-homogeneous variances across segments.

\section{Simulation Experiments.}

In this section. we present the results of simulation experiments to analyze the size and power of the tests. the coverage rates of the confidence intervals for the break dates and the adequacy of the various methods to select the number of structural changes. A wide variety. 
of lata generating processes are considered allowing different variances for the residuals and different distributions for the regressors across segments as well as scrial correlat ion. All computations are perfomed in GNUSS using a computer progran that is availathe on request for non-profit academic use (see Bai and Perron (1999) for a thorough description of the features of this programin).

\subsection{The case with no break.}

IVe stant with the case where the data generating processes exhibit nes structural change and.

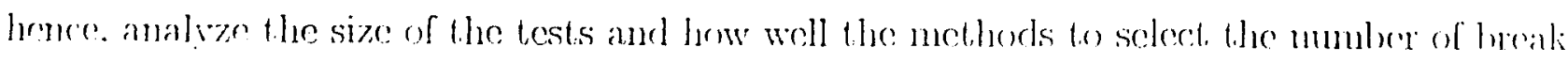
prints actually select none. Througlout $\left\{c_{t}\right\}$ denotes a secpuence of $i . i . d . N(0.1)$ randenu

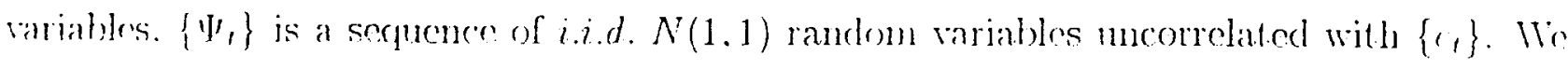
use sample sizes of $T=120$ and $T=240$. The values of the trimming $\epsilon$ and the maximum number of breaks ( $(\mathrm{J})$ considered are: $\epsilon=.05$ and $M=5, \epsilon=.10$ and $M=5, \epsilon=.15$ and $. M=5 . \epsilon=.20$ and $M=3, \epsilon=.25$ and $M=2$. In all cases, 2,000 replications are uscd.

The data generating processes and the corresponding regressors used arc:

- DGP-1: $y_{t}=e_{t}$ and $z_{t}=\{1\}(q=1)$;

- DGP-2: $y_{t}=\Psi_{t}+\epsilon_{t}$ and $z_{t}=\left\{1, \Psi_{t}\right\}(q=2)$;

- DGP-3: $y_{t}=0.5 y_{t-1}+e_{t}$ and $z_{t}=\left\{1, y_{t-1}\right\}(q=2)$.

- DGP-4: $y_{t}=v_{t}$ with $v_{t}=0.5 v_{t-1}+e_{t}$ and $z_{t}=\{1\}(q=1)$;

- DGP-5: $y_{t}=v_{t}$ with $v_{t}=e_{t}+0.5 e_{t-1}$ and $z_{t}=\{1\}(q=1)$;

- DGP-6: $y_{t}=v_{t}$ with $i_{t}=e_{t}-0.3 c_{t-1}$ and $z_{t}=\{1\}(q=1)$;

The DGP-1 with i.i.d. data is a base case to assess the basic properties of the tests and methods to select the number of breaks. It is useful to assess the effect of allowing different variances of the errors across segments and/or serial corrclation when these features are not present. The DGP-2 is a variation which includes an exogenous regressor. DGP-3 is one where serial correlation is taken into account parametrically. DGPs 4 to 6 are used to assess the effect of serial correlation in the errors and how well the corrections for its presence leads to tests with adequate sizes.

The results are presented in Table 1. Consider first, the base case represented by DGP-1 where the series is white noise. With the specification cor ${ }_{-} u=0$ and het $u=0$ all t.est.s 
have the right size for any walue of the trimming $E$. As expected. the secpucutial procedure wheses me herak around 95\% of the time. The BIC betwen 94\% and $98 \%$ (depending on $三$ ) and the $L . M Z 100 \%$ of the time. When different varianess of the resicluals are allowed acress sergumts. we see substantial size distortions when the trimming is small. These. howerer.

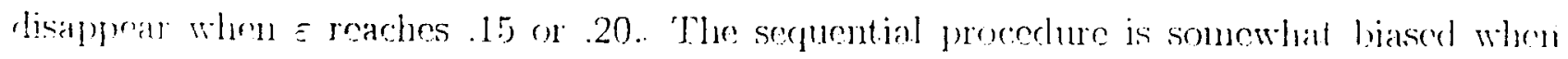
$=-0.5$ but this bias disappons quickly as som as ₹ maches . 10. Sinilar sizo distontions

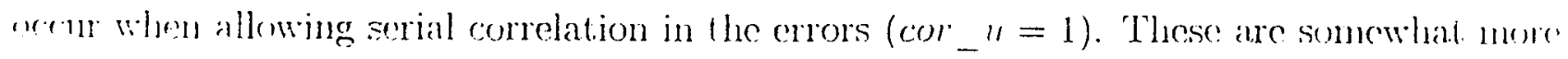
smere if. in additions. different varianese are allowed. When het_l $=0$, the sequential

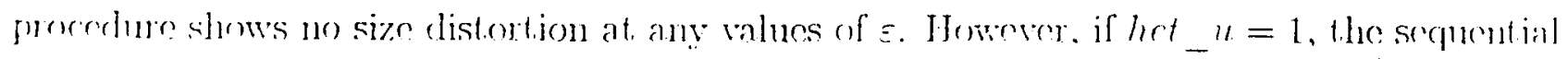
promedure is adequate only if $\varepsilon$ is at least .15.

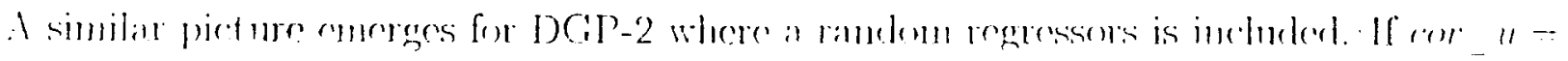
het $"=0$ all tests have the right size. Howerer. allowing for either differmt valiances

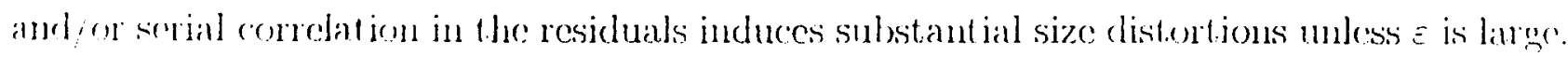
When no serial comelation is allowed, the procedures have the right size if $\Xi$ is at least . 15: $=$ when serial correlation is allowed a larger valuc is needed.

The results for DGP-3, which is an AR(1), show's that if one is testing against a large mumber of breaks (or using the WD max test) there are some distortions even if cor $u=$ het_u=0 when $\Xi$ is small. The sequential procedure romains, however, adequate for any ralues of $\Xi$. If different rariances are allowed size distortions occur unless $\Xi$ is at. least .2n.

The DGPs 4 to 6 are cases where serial correlation is present in the residuals. As cxpected. if cor_u $=0$, all procedures show substantial size distortions (with positive correlation the tests are liberal and with negative correlation they are conscrvative). It is therefore important to correct for scrial correlation. This, however, can be done adequatedy only if a large trimming is used, .15 or .20 depending on the cases. An interesting feature, howerer. is that the sequential procedure works very well for any values of $\varepsilon$ when the variances are constrained to be the sane (het_ $u=0$ ). In particular, it performs much better than the information criterion $B I C$ (and also $L W Z$ in the case of positive $A R$ errors).

In summary, if no serial correlation is present and allowed for, all procedures work woll for any values of the trimming $\varepsilon$ when the specification $c o r \_u=h e t \_u=0$ is used. If serial correlation is present a larger value of the trimming is needed when constructing the tests using the specification cor_ $u=1$. This is also the case if different variances are allowed across segments. Also, the results show the sequential procedure to perform quite well for any values of the trimming provided one is correcting for serial correlation when needed aurl not correcting for it when it is not needed. 


\subsection{The case with one break.}

Thr basic dat a genorating process considered is (Case 1):

$$
\begin{array}{ll}
y_{t}=\mu_{1}+\gamma_{1} \Psi_{1}+c_{t} . & \text { if } t \leq[0.5 T] . \\
y_{t}=\mu_{2}+\gamma_{2} \Psi_{t}+c_{t} . & \text { if } t=[0.5 T] .
\end{array}
$$

Where $\Psi_{1},-i . i, N(1,1)$ and $e_{l} \sim$ i.i.d $N(0,1)$ and both are uncorrelated. Since, no serial comedat ins is present in the crrors and no change in the distribution of the data or the errems is allewerl. wo use the specification cor_u $u=$ het_ $u=0$ and $\varepsilon=0.5$. For the trests. we wase het $z=1$ and to construct the confidence intervals on the break dates, we use het $z=0$. Wr consider three types of shifts: a) a change in interecplonly $\left(\gamma_{1}=\gamma_{2}=1\right)$, h) a change in slope only $\left(\mu_{1}=\mu_{2}=0\right)$, and $\left.c\right)$ a simultaneous change in slope and intercept.

Wi also consider a variation without the regressor $\Psi_{i}^{*}$ with crors that are serially conclated:

- Ciase 2: $i_{1}=-_{2}=0$, and $c_{t}$ replaced by $v_{t}=0.5 i_{t-1}+e_{t}$. Herc $z_{1}=\{1\}$.

In this second case, we use the specifications cor_ $u=1$, het_ $u=0$ and $\equiv=.20$. Again. for the tests. we use het ${ }_{-} \tilde{z}=1$ and to construct the confidence intervals on the break dates. we use het_z $z=0$. The experiments are performed for $T=120$ and $T=240$ and again 2.000 replications are used.

The results are presented in Table 2. Row (a) presents a case with a small change in intercept only: Here the power of the test is rather low and the curcrage rate of the break date is imprecise. We shall use this base case to investigate what increases power. There are, nevertheless, some features of interest. First, the power of the sup $F(k)$ test is decreasing as $k$ increases (more so as $k$ reaches 5 ; not shown). However, both $D$ max tests have power as high as the case with $k=1$ (which gives the highest power). Also, of the three methods to select the number of breaks, the sequential methods works best. The criterion $L H^{\circ} Z$ is quite inaccurate since it chooses no break $98 \%$ of the times. Row (b) considers the same specifications but doubling the sample size to 240 . The power of the tests increases, the sequential method selects 1 break more often and the coverage rate is better but not to a great extcnt. For comparisons, row (c) keeps $T=120$ but doubles the size of the shift in intercept. Here power increases a lot, the sequential procedure chooses $m=195 \%$ of the time and the exact coverage rate is close to the nominal $95 \%$. Hence, we can conclude that what is important is not the size of the sample but the size of the break. 
Row (1) presents the case of a mild change in slope. Again, the power of the supf $F$ (li) derrintere as $k$ increases but the $D$ max tests have as high power as the sup $F(1)$ test. Also.

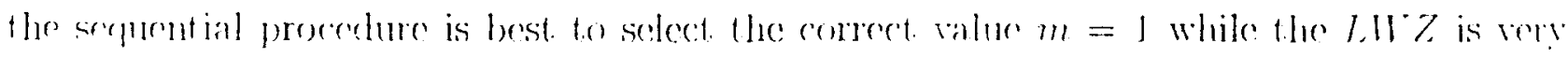
inacrumate. Row (e) considers nerging the small shifts in intereept and slope. We see that

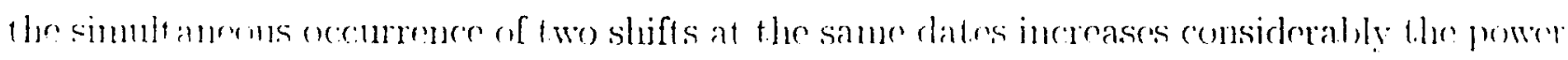
of the trests and the precision of the selected mumber of breaks. as well as the coverage rate of the break date (much more than an incrase in sample size). Rows (c) and (f) consider a larger ebange in slope only and larger simultaneous changes, respectively. Here, the penere of the tests is one. In such cases, the coverage rates are accurate and all uncthorls seldect the comect munber of breaks accurately:

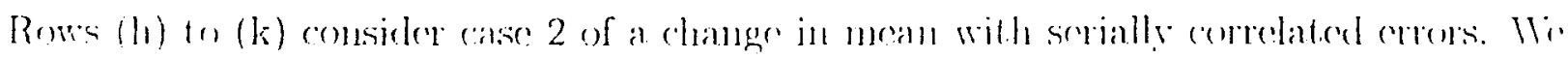
see that the presence of sexial corrclation decreases the power of the test substantially: Here. for a giren shift. doubling the sample sizo induces a negligible increase in power and in the: arcuracy of the selection methods or corerage rates. Neyertheless, the corerage mates arre

$=$ quite accurate which shows that the non-parametric correction for the presence of serial conrelation secens w be effertive.

\subsection{The case with two breaks.}

For Case 1. the basic structure is similar except that now the data gencrating process is:

$$
\begin{array}{ll}
y_{t}=\mu_{1}+\gamma_{1} \Psi_{t}^{*}+e_{t}^{*} . & \text { if } 1<t \leq[T / 3] . \\
y_{t}=\mu_{2}+\gamma_{2} \Psi_{t}^{*}+e_{t}^{*} . & \text { if }[T / 3]<t \leq[2 T / 3], \\
y_{t}=\mu_{3}+\gamma_{3} \Psi_{t}^{*}+e_{t}^{*} . & \text { if }[2 T / 3]<t<T .
\end{array}
$$

whore

$$
\begin{array}{ll}
\Psi_{t}^{*} \sim \text { i.i.d } N\left(\varsigma_{1} .1\right) . & \text { if } 1<t \leq[T / 3] . \\
\Psi_{t}^{*} \sim \text { i.i.d } N\left(\varsigma_{2} .1\right) . & \text { if }[T / 3]<t \leq[2 T / 3] . \\
\Psi_{t}^{*} \sim \text { i.i.d } N\left(\varsigma_{3} .1\right) . & \text { if }[2 T / 3]<t \leq T,
\end{array}
$$

and

$$
\begin{array}{ll}
\epsilon_{t}^{*} \sim \text { i.i.d } N\left(0, \sigma_{1}^{2}\right), & \text { if } 1<t \leq[T / 3] . \\
e_{t}^{*} \sim \text { i.i.d } N\left(0, \sigma_{2}^{2}\right), & \text { if }[T / 3]<t \leq[2 T / 3], \\
e_{t}^{*} \sim \text { i.i.d } N\left(0, \sigma_{3}^{2}\right), & \text { if }[2 T / 3]<t \leq T .
\end{array}
$$


For Case 2. wh hase only changes in mean with serially corrclated crrors. That is

$$
\begin{array}{ll}
y_{t}=\mu_{1}+r_{t} . & \text { if } 1<t \leq[T / 3] . \\
y_{t}=\mu_{2}+r_{t} . & \text { if }[T / 3]<1 \leq[2 T / 3], \\
y_{t}=\mu_{3}+r_{t} . & \text { if }[2 T / 3] \div 1 \leq T .
\end{array}
$$

where $r_{1}=0.5 r_{t-1}+c_{1}$ with $\epsilon_{1} \sim$ i.i.d. $N(0,1)$.

Wo first romsider Case 1 where the data and errors are identically distributed across segments. that is $\sigma_{1}^{2}=\sigma_{2}^{2}=\sigma_{3}^{2}$ and $\varsigma_{1}=\varsigma_{2}=\varsigma_{3}$. Results are first presenterl in Table 3 for cases where the shifts involve either only the intercept. (rows (a) to (h)) or in the slope (rows (j) to (o)). In all cases $T=120, T_{1}=40, T_{2}=80, \varepsilon=.05$, cor_ $u=0$, het_ $u=0$. and het $z=1$ for the construction of the tests and het $z=0$ for the construction of the confidence int cruals for the break dates.

We start with a case where the detection of the number of breaks is notoriously difficult. IIere, the interept increases by some value at, $T_{1}=40$ and goes back to its original wahe - at $T_{2}=80$ ). Row (a) considers the case where this change is .5. The power is, indeed. very low and all methods basically select no break. The case where the change is 1 (row (b)) is very instructive about the usefulness of the $D \max$ tests and the $\sup F(\ell+1 \mid \ell)$ test to detcrmine the number of breaks. Here the power of the sup $F(1)$ test is very low and, hence. the sequential procedure selects 2 breaks only $31 \%$ of the time. However, the $U D$ max and IID $\max$ tests have high power ( $82 \%$ and $88 \%$, respectively). The $\sup (2 \mid 1)$ test also has high power $(73 \%)$. Hence, a useful strategy is to fist decide that some break is present basecl on the $D \max$ test. Then look at the $\sup F(\ell+1 \mid \mathcal{\ell})$ to see if more than one is present. In the example of row (b) this would lead to selecting 2 breaks $64 \%$ of the time. Another example of the usefulness of this strategy is presented in row $(\mathrm{k})$. Here there is a change in slope from 1 to 2 then back to 1 . The sequential procedure chooses 2 breaks only $69 \%$ of the time. However, the strategy discussed above would lead to select 2 breaks almost $100 \%$ of the times since the $D \max$ tests have $99 \%$ power and the $\sup F(2 \mid 1)$ has $98 \%$ power.

The case discussed above clearly show the usefulness of considering tests for multiple structural changes. As shown in Andrews (1993) a test for a single change is consistent against an alternative hypothesis of multiple changes. However, as shown here, in finite samples its power can be quite low while tests against more than one change can have much higher power. This also suggests that a mechanical application of a specific to general sequential testing procedure to select the number of breaks can be sub-optimal. Indeed, in practice it is advisable to look at the double maximum tests first to avoid such cases where it. 
is difficult to distinguish botween no brok and a single break while it is asy to distingnish betwecn mo break and more than on break.

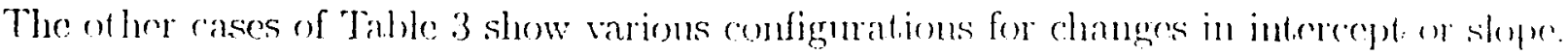
The results can be summarized as follows. First. interecpt changes of the form $\mu_{1}=0$ ) $\mu_{2}=1 . \mu_{3}=2$ (inrreasing steps) are also diflicult cases where most procedures fail to selent 1.wo breaks (the same is true for slope changres of the same fomin). In general, when the magnitude of the change is small (or difficult to identify) the coverage rates for the breali dates are too small (c.g. rows $(a, b, j, 1,0)$ ). If the changes are very large (e.g., row $\left(h_{1}\right)$ or row (f. second break)) they are too wide. However, in most cases where the mumber of hreaks is well ielentified the coverage rates are adequate.

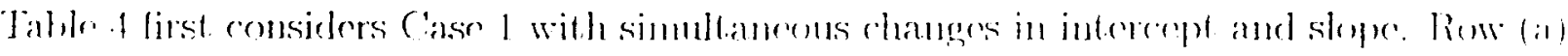
shews that very litte gain in power or accuracy of the coverage males is gained when twe shifts that are very difficult to identify individually occur simultancously. However, rows (b) and $(c)$ shows that important gains can be obtained in other cases (in particular compare $=$ row (b) of Table 4 with row (c) of Table 3 ).

The other parts of Table 4 consider Case 2 with intercept shifts and serially correlated errors with the specification cor_ $u=1$. Rows (d) to ( $\mathrm{k}$ ) consider the difficult cases where the mean return to its old value at the second break. Here power is low when the change is .5 and even 1. Hence. serial correlation induces a loss in power. The coverage rates are adequate and we conclude that the non-parametric correction for the presence of serial correlation works well. Also, we see that for given clanges in mean, an increase in the sample size has some effect on power, probably due to the fact that, for given trimming $\epsilon$, a larger number of observations allows more precise estimates of nuisance parameters related to correlation in the residuals. When the change in mean is larger, say 2 or 4 (sce rows (h) to (k)) the power of the $\sup F(1)$ test is low but the power of the $\sup F(2)$ and $\sup F(2 \mid 1)$ tests are high. Hence, a model selection strategy based on these statistic would conclude basically $100 \%$ of the times that 2 breaks are present.

Tables 5.a and 5.b consider cases where the distribution of the errors and the data are heterogenous across segments. The goal is to see if applying the required corrections lead to tests, model sclections and coverage rates that are better. Table 5 a considers data gencrated by the two breaks model with $\gamma_{1}=1, \gamma_{2}=1.5, \gamma_{3}=1.5$ and $\mu_{1}=0, \mu_{2}=1.5 . \mu_{3}=.5$. Table 5.b considers data generated by the two breaks model with $\gamma_{1}=1 . \gamma_{2}=1.5, \gamma_{3}=2$ and $\mu_{1}=0 . \mu_{2}=.5, \mu_{3}=1$. In all cases, $\sigma_{1}^{2}=\sigma_{3}^{2}=1, \varsigma_{1}=\varsigma_{3}=1$ and we vary $\sigma_{2}^{2}$ anr $\varsigma_{2}$. To ensure tests with adequate sizes, we set $\varepsilon=.15$ for the cases in Table 5 .a and wo 
"musirn $\equiv=20$ for the ases in Table 5.b. We compare the properties of the procedures using the uncorrected versions (het_z $z=1$ and het_ $u=0$ in the construction of the tests. het $z=$ het $_{-} u=0 \mathrm{in}$ the construction of the confidence intervals) and the correcter imsions (het $z=$ het_" $=1$ in the construction of the tests and in the construction of

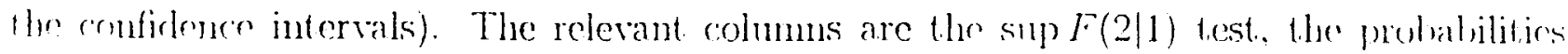
of solecting 2 breaks and the coverage rates of the break dates (note than for the sectertion procendures hased on the $B I C$ and $J I F Z$, only the uncorrected version is presculed since these methods cannot be nodificd to account for hetcrogeneity across segments).

The results show that important gains in the power of the tests can be obtained when allowing for different distribution of the errors across segnents. In almost all cases, the power of the suph(2/1) test is higher when corrected. For example, in Tahbe 5.b when the rartiune of the errors is four times higher in the middle segment (and the mean of the regressirs is also 4 times higher) and $T=120(\mathrm{row}(\mathrm{g}))$, the power of the uncorrected version is .53 white it is is when allowing for different variances. This also translates into a higher probability -of selecting two breaks. $76 \%$ instead of $52 \%$ making the sequential procedure more arlequate to select the number of breaks than the BIC. Even stronger comparisons obtain with the second case presented in Table 5.b. For example, in row $(\mathrm{g})$ we see an increase in the power of the $\sup F(2 \mid 1)$ test and the probability of choosing 2 breaks rising from $22 \%$ to $60 \%$. The results also show that correcting for hetcrogeneity in the data improves the corerage rates of the confidence intervals of the break dates.

\section{Summary and Practical Recommendations.}

The simulations have shown the tests, model selection procedures and the construction of the confidence intervals for the break dates to be useful tools to analyze models with multiple breaks. IIowerer, care must be taken when using particular specifications. We make the following recommendations.

- First, ensure that the specifications are such that the size of the tests are adequate under the hypothesis of no break. If serial correlation and/or heterogeneity in the data or errors across segments are not allowed in the estimated regression model (and not present in the DGP), using any ralue of the trimming $\varepsilon$ will lead to tests with adequate sizes. However, if such features are allowed, a higher trimming is necded. The simulations show that, with a sample of $T=120, \varepsilon=.15$ should be enough for heterogeneity in the crrors or the data. If serial correlation is allowed, $\varepsilon=.20$ may bo 
mended. These could be reduced if larger sample sizes are arailable.

- Orerall. selecting the break point using the $B I C$ works well when breaks are present but liss so under the null hypothesis, especially if serial correlation is present. The menther hased on the $L I F Z$ criterion works better under the mull hypothesis (even with srrial (orrelation) by inposing a higher ponalty. I Iowerer, this higher penalty translates into a rery bad performance when breaks are present. Also, nodel selection procedures

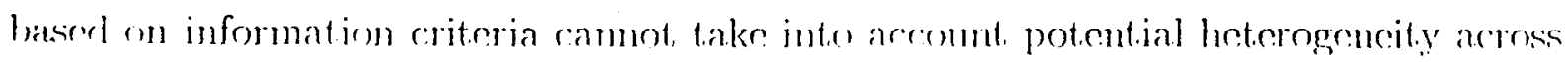
segments milike the sequential method. Overall, the sequential procedure works best. in sorrecting the number of breaks.

- There ane impertant instances where the perfomane of the secenential procedure can be improred. A useful strategy is to first look at the UD max or IV D max tests to sec if at least a break is present. Then the number of breaks can be decided based upon an examination of the sup $F(f+1 \mid f)$ statistics const ructed using estimates of the break dates obtained from a global minimization of the sum of squared residuals. This is, in our opinion. the preferred strategy:

- The power of the UD max or WD max tests is almost as high as the porrer of a test of no change versus an alternative hypothesis that specifies the true number of changes. This provides added justifications for its use in practice.

- The coverage rates for the break dates are adequate unless the break is either too small (so small as not to be detected by the tests) or too big. This is, from a practical point of view, however, an encouraging result. The confidence intervals are inadequate (in that they miss the true break value too often) exactly in those cases where it would be quite difficult to conclude that a break is present (in which case they would not be used anyway). When the breaks are very large the confidence intervals do contain the true values but are quite wide leading to a conservative assessment. of the accuracy of the estimates. It was found that correcting for heterogeneity in the data and/or errors across segments yields improvements over a more straightforward uncorrected interval. Correcting for serial correlation also does lead to substantial improvements.

- Correcting for heterogeneity in the distribution of the data or the errors and for serial correlation also improves the power of the tests and the accuracy in the selection of the number of breaks. 


\section{References}

[1] Androws, D.W.K. (1991): "Ileteroskedasticity and Antocorrelation Consistont Conariance Matrix Estimation." Economeltica 59, 817-85,8.

|2| Amdrews. J.W.K. (1993): "Tests for Parameter Instability and St.ructural Change with Unkmown Change Point.," Econometrica 61, $821-850$.

[3] Andrews, D.W.K. and J.C. Monahan (1992): "An Improwed Hoteroskedasticity and Autocorrelation Consistent Covariande Natrix Estimator," Econometrica 60, 95,3-9660.

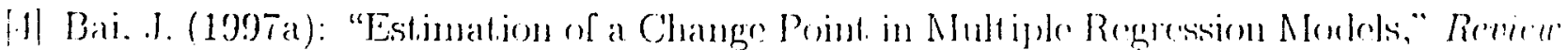
of Eronomic and Statistics 79, 551-5033.

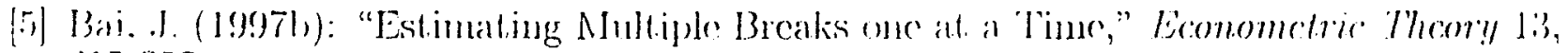
$315-352$.

(6) Bai. I. and P. Porron (1998): "Estinating and Testing Lincar Nodels with Mluttipte Structural Changes," Economctrica 66, 47-78.

[7] Bai. J. and P. Perron (1999): "Computation and Analysis of Muliple Structural Change" Models," manuscript, Boston University. .

- $[8]$ Lin. J., S. Wir. and J.V. Zidek (1997): "On Segmented Multivariate Regressions," Statistica Sinica T, 497-525.

[9] Perron. P. (1997): "L'estimation de modeles arec changenents structurels multiples." Actualité Économique $73,457-505$.

[10] Yao, Y-C. (1988): "Estimating the Number of Change-Points via Schwarz: Criterion." Statistics and Probability Letters 6, 181-189. 
Table 1: Size of the tests and probabilities of selecting breaks

\begin{tabular}{|c|c|c|c|c|c|c|c|c|c|c|c|c|c|c|c|}
\hline \multirow[b]{2}{*}{ 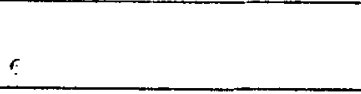 } & \multicolumn{5}{|c|}{ DGP-1 } & \multicolumn{5}{|c|}{$D G \mathrm{C}-2$} & \multicolumn{5}{|c|}{ DGP-3 } \\
\hline & i) 5 & .10 & .15 & .20 & .25 & .05 & .10 & .15 & .20 & .25 & .05 & .10 & .15 & .20 & 25 \\
\hline $\begin{array}{l}\cos ^{u}=0 . \text { het } u=0 \\
\operatorname{sil} F(1)\end{array}$ & .05 & .) 1 & .05 & .04 & .0 .1 & .05 & .011 & . 11.5 & .05 & (1): & .05 & .06 & (1) & .0 .5 & $.6 \mathrm{i}$ \\
\hline $\sup F(2)$ & .05 & .015 & .05 & .04 & .0.4 & 0.1 & .04 & .01 & .015 & .05 & .00 & tot & .08 & .07 & . 6 \\
\hline сир $F(3)$ & .0 .5 & .05 & .04 & .0 .3 & & .015 & .05 &.$(1.1$ & 5 & & .09 & .09 & $.0 S$ & .07 & \\
\hline sulp $F(1)$ & $.06 j$ & (15) & .04 & & & . & .106 & .01 & & & .12 & .11 & .08 & & \\
\hline sup $F(5)$ & .06 & .05 &.$(0) 4$ & & & .08 & 01 & . O3 & & & .15 & .12 & .07 & & \\
\hline LDMAX & .0.5 & .0 .1 & .015 & .04 & .04 & .015 & .014 & .15 & .05 & .05 & .00 & .06 & .07 & .116 & ז) \\
\hline$\| D M A X$ & .06 & .05 & .04 & .0 .4 & .04 & .006 & .05 & .015 & (1).5 & .05 & .10 & .09 & .09 & $.0 \bar{\gamma}$ & .06 \\
\hline Sorpura $\quad r r \mid m=0)^{\prime}$ & 5: & .96 & .95 & .96 & .96 & .95 & .96 & .9 .5 & .95 & .95 & .95 & i & .91 & $4 \pi$ & .91 \\
\hline$S e q u n-r r ! m=1 !$ & .05 & .11 .4 & .05 & .1 .1 & .01 & .05 & .0 .4 & .05 & .015 & . (1).5 & .05 & .05 & .06 & .05 & $.1) 6$ \\
\hline Srquen - Irim - 2 & .010 & (II) & $.0(1)$ & .00 & $.00)$ & .80 & .110 & .610 & .00 & $(0)$ & $.0(1)$ & .00 & $.0(1)$ & .00 & .100 \\
\hline 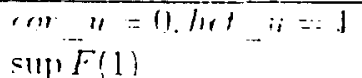 & $.10)$ & .00 & .06 & .05 & 0.4 & 16 & (IS & 117 & $0 \mathrm{og}$ & 05 & 18 & 10 & 10 & 0 & 07 \\
\hline थㅏ $\Gamma(2)$ & .24 & 11 & . 18 & .06 & .06 & .35 & .1 .1 & 0 & .116 & .06 & .40 & .22 & .11 & .10 & 115 \\
\hline sир $F(? ;)$ & .21 & .11 & .07 & .05 & & .12 & .17 & .08 & $(1) \pi$ & & .49 & .20 & .11 & .11 & \\
\hline suा $F(1)$ & .29 & .11 & .07 & & & .48 & .19 & .18 & & & .59 & .29 & .15 & & \\
\hline $\sup F(5)$ & .31 & .12 & .06 & & & .53 & .18 & i & & & .65 & .30 & .13 & & \\
\hline CDMAX & $.2 \bar{\imath}$ & .10 & .06 & & .04 & .46 & .14 & .08 & .06 & .06 & .51 & .17 & .13 & 落. & $0 \$$ \\
\hline$" M D M A$ & .33 & .12 & .07 & .06 & .05 & .57 & .19 & .10 & .07 & .06 & .60 & .27 & .16 & .10 & .08 \\
\hline$S \in q u a-P_{r}^{\prime} m=0$ & .90 & .94 & .94 & .95 & .96 & .85 & .92 & .93 & .94 & .95 & .82 & .90 & .90 & .93 & .93 \\
\hline Sequa - Prim $=1$ & .09 & .06 & .06 & .05 & .04 & .14 & .08 & .07 & .06 & .05 & .16 & .09 & .09 & .07 & .07 \\
\hline$S \epsilon q u a-\operatorname{Pr}[m=2]$ & .01 & .00 & .00 & .00 & .00 & .01 & .00 & .00 & .00 & .00 & .02 & .01 & .01 & .00 & .00 \\
\hline $\begin{array}{l}\operatorname{cor} \_u=1 . \text { het } u=0 \\
\operatorname{sun} F(1)\end{array}$ & 06 & 06 & 06 & 05 & 05 & 08 & 06 & 00 & 7 & ד0 & & & & & \\
\hline $\sup F(2)$ & .08 & .08 & .07 & .06 & .06 & .10 & .09 & .09 & .08 & .08 & & & & & \\
\hline $\sup F(3)$ & .11 & .10 & .08 & .05 & & .14 & .12 & .10 & .08 & & & & & & \\
\hline $\sup F(t)$ & .15 & .12 & .08 & & & .18 & .16 & .10 & & & & & & & \\
\hline sup $F(5)$ & .21 & .14 & .07 & & & .23 & .20 & .10 & & & & & & & \\
\hline ¿D.MAX & .08 & .07 & .07 & .06 & .05 & .12 & .09 & .08 & .08 & t & & & & & \\
\hline "WD.MA & .14 & .11 & .08 & .06 & .05 & .21 & $.1 \bar{i}$ & .11 & .09 & .07 - a - a & & & & & \\
\hline$S_{e q u a}-\operatorname{Pr} \dot{m}=0$ & .94 & .95 & .94 & .95 & .95 & .92 & .9 .1 & .93 & .93 & .93 & & & & & \\
\hline Sequa $-\operatorname{Pr}[m=1]$ & .06 & .05 & .06 & .05 & .05 & .07 & .06 & .07 & .07 & .07 & & & & & \\
\hline Sequa $\left.-P_{r} \mid m=2\right\}$ & .00 & .00 & .00 & .00 & .00 & .01 & .00 & .00 & .00 & .00 & & & & & \\
\hline $\begin{array}{l}\operatorname{cor}_{\sup }-u=1 . \text { het_} \_u=1 \\
\operatorname{sul}\end{array}$ & .12 & .08 & i & .05 & .05 & .25 & .14 & .11 & .10 & .08 & & & & & \\
\hline $\sup F(2)$ & .29 & .14 & .10 & .07 & .07 & .54 & .31 & .19 & .13 & .10 & & & & & \\
\hline $\sup F(3)$ & .32 & .15 & .10 & .07 & & .65 & .39 & .22 & .15 & & & & & & \\
\hline $\sup F(1)$ & 37 & .16 & .09 & & & .75 & .44 & .25 & & & & & & & \\
\hline $\sup F(\bar{j})$ & .39 & .16 & .09 & & & .81 & .48 & .24 & & & & & & & \\
\hline CDMAX & .36 & .14 & .09 & .07 & .05 & .75 & .35 & .18 & .12 & .09 & & & & & \\
\hline$W D . M A X$ & .43 & .17 & .10 & .07 & .06 & .86 & .49 & .24 & .15 & .10 & & & & & \\
\hline Sequa $-\operatorname{Pr}[m=0]$ & .88 & .92 & .93 & .95 & .95 & .75 & .86 & .89 & .90 & .92 & & & & & \\
\hline Sequa $-\operatorname{Pr} \mid m=1$ & .11 & .08 & .07 & .05 & .05 & .21 & .13 & .11 & .10 & .08 & & & & & \\
\hline Sequn $-\operatorname{Pr}[m=2]$ & .01 & .00 & .00 & .00 & .00 & .04 & .01 & .00 & .00 & .00 & & & & & \\
\hline$\overline{B B I C-\operatorname{Pr}[m=0]}$ & .94 & .96 & .97 & .98 &.$\overline{98}$ & .97 & .98 & .99 & .99 & .99 & .97 & .98 & .98 & .98 & .99 \\
\hline$B I C-\operatorname{Pr}[m=1]$ & .04 & .03 & .03 & .02 & .02 & .03 & .02 & .01 & .01 & .01 & .03 & .02 & .02 & .02 & .01 \\
\hline$B I C-l^{\prime} r[m=2]$ & .02 & .01 & .00 & .00 & .00 & .00 & .00 & .00 & .00 & .00 & .00 & .00 & .00 & .00 & .100 \\
\hline$L H Z-\operatorname{Pr}[m=0]$ & 1.0 & 1.0 & 1.0 & 1.0 & 1.0 & 1.0 & 1.0 & 1.0 & 1.0 & 1.0 & 1.0 & 1.0 & 1.0 & 1.0 & 1.0 \\
\hline$\left[\mathrm{II}^{\circ} Z-\operatorname{Pr} m=1\right]$ & .00 & .00 & .00 & .00 & .00 & .00 & .00 & .00 & .00 & .00 & .00 & .00 & .00 & .00 & .00 \\
\hline$L H Z-P r m=2$ & .00 & .00 & .00 & .00 & .00 & .00 & .00 & .00 & .00 & .00 & .00 & .00 & .00 & .00 & .00 \\
\hline
\end{tabular}


Table 1 (cont d): Size of the tests and probabilitics of selecting breaks

\begin{tabular}{|c|c|c|c|c|c|c|c|c|c|c|c|c|c|c|c|}
\hline \multirow[b]{2}{*}{$\leftarrow$} & \multicolumn{5}{|c|}{ DGP-1 } & \multicolumn{5}{|c|}{$D G P-5$} & \multicolumn{5}{|c|}{ DGP-6 } \\
\hline & .155 & 10 & .15 & 20 & .25 & .05 & .10 & .15 & 20 & 25 & .015 & .10 & .15 & 20 & 25 \\
\hline 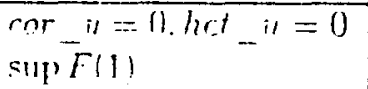 & .52 & .52 & .50) & .44 & .44 & .24 & .21 & 21 & .21 & .20 & .00 & .00 & (1)0 & .00 & .00 \\
\hline sup $F 12$ & .82 & $.7 T$ & .69 & .59 & .53 & .12 & .38 & .34 & .29 & .24 & .00 & .00 & .00 & .00 & (m) \\
\hline silp $F$ & .90 & .84 & .74 & .60 & & .51 & .44 & .39 & .30 & & .00 & .00 & .00 & .00 & \\
\hline sup $F$ & .94 & .89 & .75 & & & .60 & .49 & .39 & & & .00 & .00 & .00 & & \\
\hline$\leqslant 11) F$ & .95 & .89 & .71 & & & .67 & .53 & .36 & & & .00 & .00 & .00 & & \\
\hline$[D . M$ & .81 & .73 & .04 & .53 & .49 & .38 & .33 & .31 & .25 & .23 & .00 & .00 & .00 & 000 & .00 \\
\hline$\| D D . U$ & .92 & .85 & .73 & .59 & .53 & .55 & 46 & .38 & .28 & .24 & .00 & .00 & .00 & .00 & .00 \\
\hline$S \cdot q m-\Gamma r m=0$ & .48 & .49 & .50 & .50 & .56 & .70 & .76 & .76 & .79 & .80 & 1.0 & 1.0 & 1.0 & 1.0 & 1.0 \\
\hline Srqum - Prim = & .29 & .31 & .33 & .31 & .35 & 18 & .18 & 21 & .18 & .18 & .00 & .(1)( & .00 & .110 & . \\
\hline Sru!n $-\Gamma, \Gamma)=2$ & .16 & .15 & .14 & .12 & .09 & .05 & .05 & .03 & .03 & .02 & .00 & .00 & .00 & .00 & 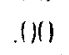 \\
\hline $\begin{array}{l}\operatorname{cor}{ }^{13}=0 . \text { het }{ }^{1}=1 \\
\text { sily } \Gamma_{11} 1\end{array}$ & 61 & 58 & .52 & .46 & .44 & .35 & .30 & .28 & .22 & 21 & .01 & . 100 & .00 & $.00)$ & .0101 \\
\hline$=11, F 2$ & .92 & .44 & .72 & .62 & .56 & .70 & .51 & .41 & .31 & 27 & .04 & .00 & .00 & .101 & .110 \\
\hline $511, F(3)$ & .96 & .89 & .7 & .64 & & .70 & $.5 \pi$ & 15 & 33 & & .02 & .00 & .00 & (6) & \\
\hline sup $F$ & .98 & .92 & .78 & & & .84 & .63 & .46 & & & .03 & .00 & .00 & & \\
\hline sup $F$ & .99 & .93 & .76 & & & .87 & .65 & .43 & & & .02 & .00 & .00 & & \\
\hline$[\because D .1$ & .96 & .8 .1 & .70 & .57 & .51 & .77 & .49 & .38 & .27 & .24 & .04 & .00 & .00 & (n) & .00 \\
\hline$\| D M$ & .98 & .92 & .78 & .62 & .55 & .85 & .62 & .40 & .31 & 27 & .04 & .00 & .00 & .0() & .110 \\
\hline Seque - Prin & .39 & .42 & .48 & .55 & .56 & .05 & .70 & .73 & .78 & .79 & .99 & 1.0 & 1.0 & 1.0 & 1.0 \\
\hline Sequa $-P r i$ & 27 & .32 & .33 & .32 & .35 & .23 & .23 & .23 & .19 & .19 & .01 & .00 & .00 & .00 & .00 \\
\hline Scqun $-P r !$ & .21 & .18 & .15 & .12 & .09 & .09 & .06 & .04 & .03 & .02 & .00 & .00 & .00 & .00 & .00 \\
\hline $\begin{array}{l}\operatorname{cor}_{\sup } \bar{F}(1)\end{array}$ & .07 & .08 & .08 & .07 & .07 & .09 & .08 & .10 & .08 & .08 & .03 & .03 & .03 & .03 & .03 \\
\hline $\sup F(2)$ & .12 & .14 & .12 & .10 & .09 & .15 & .16 & .14 & .12 & .11 & .05 & .04 & .04 & .03 & .03 \\
\hline $\sup F(3)$ & .22 & .21 & .16 & .10 & & .25 & .22 & .17 & .12 & & $.0 T$ & .06 & .04 & .03 & \\
\hline $\sup F$ & .34 & .28 & .17 & & & .38 & .29 & .18 & & & .11 & .08 & .05 & & \\
\hline $\sup F($ & .46 & .32 & .15 & & & $4 \pi$ & .32 & .17 & & & .15 & .09 & .04 & & \\
\hline LD.M & .18 & .14 & .11 & .08 & .08 & .18 & .14 & .12 & .10 & .08 & .0 & .03 & .03 & .03 & .03 \\
\hline WD.M & .35 & .27 & .15 & .11 & .08 & .36 & .20 & .17 & .12 & .10 & .09 & .06 & .05 & .03 & .03 \\
\hline Sequa $-P r: m$ & .93 & .92 & .92 & .93 & .93 & .91 & .92 & .91 & .92 & .93 & .97 & .97 & .97 & .97 & ד \\
\hline Sequn - Prim & .06 & .08 & .08 & .06 & .07 & .08 & .08 & .09 & .08 & .07 & .03 & .03 & .03 & .03 & .03 \\
\hline Sequn - Prim & .01 & .00 & .00 & .00 & .00 & .01 & .00 & .00 & .00 & .00 & .00 & .00 & .00 & .00 & .00 \\
\hline $\begin{array}{l}\operatorname{cor}_{-} u=1 . \text { het } u=1 \\
\sup F(1)\end{array}$ & .22 & .15 & .13 & .08 & .08 & .18 & .13 & .11 & .09 & .08 & .04 & .02 & .02 & .()2 & .02 \\
\hline sup $F$ & .56 & .36 & .23 & .14 & .12 & .51 & .28 & .19 & .13 & .11 & .11 & .04 & .03 & .02 & .02 \\
\hline $\sup F($ & .64 & .41 & .26 & .15 & & .56 & .31 & .21 & .13 & & .10 & .03 & .02 & .02 & \\
\hline sup $F l$ & .76 & .47 & .28 & & & .65 & .34 & .21 & & & .11 & .03 & .02 & & \\
\hline & .82 & .51 & .28 & & & .70 & .37 & .19 & & & .10 & .03 & .02 & & \\
\hline C'D.IJ & .75 & .39 & .24 & .11 & .0 & .62 & .20 & .17 & .11 & .09 & .11 & .03 & .02 & .02 & .02 \\
\hline$H F D$. & .84 & .52 & .31 & .15 & .11 & .7 & .30 & .21 & .13 & .11 & .14 & .04 & .03 & .02 & .02 \\
\hline Sequa - Pr & .78 & .85 & .87 & .92 & .9 & .82 & .87 & .89 & .92 & .9 & .96 & .98 & .98 & .98 & .98 \\
\hline Sequin-Pr! & .17 & .14 & .12 & .08 & .07 & .15 & .12 & .11 & .08 & .08 & .04 & .02 & .02 & .02 & .02 \\
\hline Sequa $-\operatorname{Pr}[m=2]$ & .04 & .01 & .01 & .00 & .00 & .03 & .01 & .00 & .00 & .00 & .00 & .00 & .00 & .00 & .00 \\
\hline$\overline{B I C-\operatorname{Pr} \mid n}$ & .21 & .33 & .45 & .58 & .63 & .62 & .71 & .77 & .84 & .87 & 1.0 & 1.0 & $\overline{1.0}$ & 1.0 & $\overline{1.0}$ \\
\hline$B I C-\operatorname{Pr} m$ & .11 & .20 & .25 & .23 & .20 & .13 & .13 & .1 & .12 & .1 & .00 & .00 & .00 & .00 & .00 \\
\hline$B I C-\operatorname{Pr}[m=2]$ & .21 & .24 & .22 & .17 & .11 & .15 & .12 & .07 & .04 & .02 & .00 & .00 & .00 & .00 & .00 \\
\hline$L[1 Z-P r m=0]$ & .82 & .84 & .87 & .90 & .92 & .97 & .98 & .98 & .98 & .99 & 1.0 & 1.0 & 1.0 & 1.0 & 1.0 \\
\hline$L \mathrm{H}^{\circ} Z-\operatorname{Pr}[m=1]$ & .12 & .10 & .10 & .08 & .07 & .03 & .02 & .02 & .02 & .01 & .00 & .00 & .00 & .00 & .00 \\
\hline$\left.L H^{-} Z-\operatorname{Pr} m=2\right]$ & .05 & .05 & .03 & .01 & .01 & .00 & .00 & .00 & .00 & .00 & .00 & .00 & .00 & .00 & .00 \\
\hline
\end{tabular}


Table 2: Power of the test.s and broak selection when $m=1$.

\begin{tabular}{|c|c|c|c|c|c|c|c|c|c|c|c|c|c|c|c|c|c|c|c|c|}
\hline & \multirow[b]{3}{*}{ (Aiso } & \multirow[b]{3}{*}{ Vialuess } & \multirow[b]{3}{*}{ Spresilications' } & \multicolumn{7}{|c|}{ Tosts (probualuility of rejoxtion) } & \multicolumn{9}{|c|}{ Probubility of solenting k lemaks } & \multirow{3}{*}{$\begin{array}{l}\text { Coveriane } \\
\text { Ratre } \\
9)^{\prime}: 8\end{array}$} \\
\hline & & & & \multicolumn{3}{|c|}{$\operatorname{sil} \mid \cdot(k)$} & \multicolumn{2}{|c|}{ sil) $F\left(r^{\prime}+1 \mid \gamma\right)$} & \multicolumn{2}{|c|}{$D_{\max }$} & \multicolumn{3}{|c|}{ Serfluir } & \multicolumn{3}{|c|}{ IIT } & \multicolumn{3}{|c|}{$\pi \pi$} & \\
\hline & & & & $\mathrm{I}$ & 2 & 3 & $2 \| 1$ & 312 & $T$ & $\pi$ & 0 & I & 3 & 1) & 1 & 2 & 11 & $\mathrm{~T}$ & 2 & \\
\hline il) & $\begin{array}{l}T \\
E=.05 \\
T=120\end{array}$ & $\begin{array}{l}\gamma_{1}=\gamma_{2}=1 \\
\mu_{1}=0, \mu_{2}=.5\end{array}$ & corr $u=0$ & $.4: 3$ & .35 & .3 .1 & $(0: 3$ & .111 & .12 & .12 & .57 & .13 & 112 & (i) & .3 & $.1)^{2}$ & .91 & 112 & .00 & .7 .7 \\
\hline b) & $\begin{array}{l}1 \\
\varepsilon=.05 \\
T=2110\end{array}$ & $\begin{array}{l}\gamma_{1}=\gamma_{2}=1 \\
\mu_{1}=0, \mu_{2}=.5\end{array}$ & $\operatorname{cor}_{-} u=0$ & $.6 i j$ & .53 & .50 & .02) & .01 & $\left(i_{i} \overline{3}\right.$ & 62 & .34 & .65 & .111 & (3) & $4: 3$ & .01) & $.94)$ & $.0 \mathrm{~L}$ & .00 & .80 \\
\hline (:) & $\begin{array}{l}1 \\
E=.05 \\
T=120\end{array}$ & $\begin{array}{l}\gamma_{1}=\gamma_{2}=1 \\
\mu_{1}=0, \mu_{2}=1\end{array}$ & $c o r_{-} u=0$ & .99 & .97 & .96 & .04 & (1)2 & !!! & 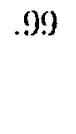 & .HI & .95 & .0) 1 & .022 & (9) & .(1):3 & $.36 ;$ & .61 & (10) & .93 \\
\hline d) & $\begin{array}{l}1 \\
\varepsilon=.05 \\
T=120\end{array}$ & $\begin{array}{l}\gamma_{1}=1, \gamma_{2}=1 . \bar{j} \\
\mu_{1}=\mu_{2}=0\end{array}$ & $\operatorname{cor}_{-} u=0$ & .79 & .69 & .665 & .033 & .01 & .78 &.$\pi$ & .21 & .77 & 02 & 28 & .69 & $.10: 3$ & $.8 T$ & 13 & .00) & .83 \\
\hline c) & $\begin{array}{l}1 \\
\varepsilon=.05 \\
T=120\end{array}$ & $\begin{array}{l}\gamma_{1}=1, \gamma_{2}=1.5 \\
\mu_{1}=0, \mu_{2}=.5\end{array}$ & $c o r_{-} u=0$ & 1.0 & .99 & .98 & .04 & .02 & 1.0 & 1.0 & (0) & .96 & .014 & .01 & .96 & .03 & .18 & .82 & .00 & .94 \\
\hline f) & $\begin{array}{l}1 \\
\varepsilon=.05 \\
T=120\end{array}$ & $\begin{array}{l}\gamma_{1}=1, \gamma_{2}=2 \\
\mu_{1}=\mu_{2}=0\end{array}$ & $\therefore o r_{-} u=0$ & 1.0 & 1.0 & 1.0 & .111 & .02 & 1.0 & 1.0 & .00 & .96 & .04 & .00 & די. & .033 & .02 & .98 & .00 & .93 \\
\hline g) & $\begin{array}{l}1 \\
\varepsilon=.05 \\
T=120\end{array}$ & $\begin{array}{l}\gamma_{1}=1, \gamma_{2}=2 \\
\mu_{1}=0, \mu_{2}=1\end{array}$ & $\operatorname{cor}_{-} u=0$ & 1.0 & 1.0 & 1.0 & .04 & .02 & 1.0 & 1.0 & .00 & .96 & .114 & .00 & .97 & .03 & .00 & 1.0 & .00 & .96 \\
\hline$\overline{\Pi_{1}}$ & $\begin{array}{l}2 \\
\varepsilon=20 \\
T=120\end{array}$ & $\mu_{1}=0, \mu_{2}=.5$ & $r_{-} r_{-} u=1$ & .25 & .27 & .30 & .04 & .00 & .30 & .31 & .75 & .21 & .111 & .32 & 45 & .18 & 65 & .29 & (1);3 & .93 \\
\hline i) & $\begin{array}{l}2 \\
\varepsilon=.20 \\
T=240\end{array}$ & $\mu_{1}=0 . \mu_{2}=.5$ & $c o r_{-} u=1$ & .38 & .34 & .31 & .02 & . 000 & .39 & .38 & .62 & .37 & 01 & 21 & .58 & .19 & $.6 t$ & .35 & .01 & .91 \\
\hline j) & $\begin{array}{l}2 \\
\varepsilon=.20 \\
T=120\end{array}$ & $\mu_{1}=0, \mu_{2}=1$ & $\operatorname{cor}-u=1$ & .66 & .61 & .61 & .03 & .00 & .68' & .69 & .34 & .63 & .02 & j) & .71 & .22 & .23 & .74 & $.0-1$ & .89 \\
\hline & $\begin{array}{l}2 \\
\varepsilon=20 \\
T=240\end{array}$ & $\mu_{1}=0, \mu_{2}=1$ & $c o r-u=1$ & .91 & .85 & .82 & .03 & .00 & (91 & .90 & . 199 & .88 & $.0 ; 3$ & .01 & .74 & .23 & to7 & .90 & .02 & .91 \\
\hline
\end{tabular}

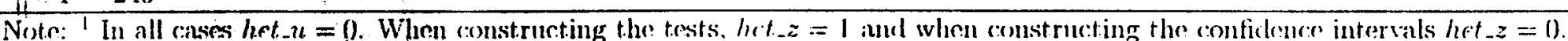


Table 3: Power of the tests and break selection when $m:=2$.

Cilse $1, T=120, \varepsilon=.05$, , cor...u $=0, \operatorname{lict}-u=0.1^{\prime}$

\begin{tabular}{|c|c|c|c|c|c|c|c|c|c|c|c|c|c|c|c|c|c|c|c|}
\hline & \multirow[b]{3}{*}{ Valluns: } & \multicolumn{7}{|c|}{ Trest.s (probability of rejection) } & \multicolumn{9}{|c|}{ Probablility of solecting $k$ breaks } & \multicolumn{2}{|c|}{ Cowrikge } \\
\hline & & \multicolumn{3}{|c|}{$\sin F(k)$} & \multicolumn{2}{|c|}{$\sin F\left(\rho+1 \mid r^{\prime}\right)$} & \multicolumn{2}{|c|}{ Dmax } & \multicolumn{3}{|c|}{ Secplui } & \multicolumn{3}{|c|}{$B I C$} & \multicolumn{3}{|c|}{$\angle I V Z$} & \multirow{2}{*}{$\begin{array}{l}\text { liatu } \\
\text { H.1 }\end{array}$} & \multirow{2}{*}{$\begin{array}{l}95^{2}: 1 \\
112\end{array}$} \\
\hline & & 1 & 2 & 3 & $2 \mid 1$ & $3 \mid 2$ & $\bar{l}$ & $W$ & (0) & 1 & 2 & 1) & 1 & 2 & 0 & 1 & 2 & & \\
\hline i) & $\begin{array}{l}\gamma_{1}=\gamma_{2}=\gamma_{3}=1 \\
\mu_{1}=\mu_{3}=0, \mu_{2}=.5\end{array}$ & .13 & .23 & .26 & .11 & .01 & .18 & .25 & .87 & .11 & .02 & .90 & $.06 \mathrm{i}$ & .14 & $1.1)$ & .00 & .011 & .51 & .19 \\
\hline h) & $\begin{array}{l}\gamma_{1}=\gamma_{2}=\gamma_{3}=1 \\
\mu_{1}=\mu_{3}=0, \mu_{2}=1\end{array}$ & .41 & .89 & .89 & .73 & .03 & .82 & .88 & is!) & .08 & .31 & .31 & $.0 . \overline{5}$ & .62 & .98 & .00 & .02 & ז & $.8 \bar{i}$ \\
\hline c) & $\begin{array}{l}\hat{\gamma}_{1}=\gamma_{2}=\gamma_{3}=1 \\
\mu_{1}=0, \mu_{2}=1, \mu_{3}=2\end{array}$ & 1.0 & 1.0 & 1.0 & .56 & .03 & l.0 & 1.0 & $.01)$ & .44 & .54 & $.00)$ & .38 & (1) & (14) & .96 & .0 .4 & .ss & .56 \\
\hline (d) & $\begin{array}{l}\gamma_{1}=\gamma_{2}=\gamma_{3}=1 \\
\mu_{1}=0, \mu_{2}=1, \mu_{3}=-1\end{array}$ & 1.0 & 1.0 & 1.0 & .86 & .04 & 1.0 & 1.0 & .00 & 11 & 82 & .0() & $.1: 3$ & $.3: 3$ & (1)2 & .67 & .31 & .89 & .96 \\
\hline i) & $\begin{array}{l}\eta_{1}=\gamma_{2}=\gamma_{3}=1 \\
\mu_{1}=0, \mu_{2}=-1, \mu_{3}=2\end{array}$ & 1.0 & 1.0 & 1.0 & .86 & .05 & 1.0 & 1.0 & .100 & .14 & .82 & .00 & .13 & .82 & .00 & .71 & .29 & .83 & .99 \\
\hline g) & $\begin{array}{l}\gamma_{1}=\gamma_{2}=\gamma_{3}=1 \\
\mu_{1}=0, \mu_{2}=1, \mu_{3}=3\end{array}$ & 1.0 & 1.0 & 1.0 & .83 & .06 & 1.0 & 1.0 & .00 & 17 & Ti & .00 & .15 & .80 &.$(0)$ & .75 & .25 & .88 & .96 \\
\hline h) & $\begin{array}{l}\gamma_{1}=\gamma_{2}=\gamma_{3}=1 \\
\mu_{1}=0, \mu_{2}=2, \mu_{3}=-1\end{array}$ & 1.0 & 1.0 & 1.0 & 1.0 & .05 & 1.0 & 1.0 & .(0) & $.00)$ & 95 & .00 & .170 & .96 &.$(3)$ & .00 & 1.0 & '95 & $.9 !)$ \\
\hline j) & $\begin{array}{l}\gamma_{1}=\gamma_{3}=1, \gamma_{2}=1.5 \\
\mu_{1}=\mu_{2}=\mu_{3}=0\end{array}$ & .22 & 49 & .52 & .28 & .03 & .40 & .j() & .78 & .14 & .117 & .75 & .08 & .16 & 1.0 & .00 & $.0(1)$ & iT & .66 \\
\hline k) & $\begin{array}{l}\gamma_{1}=\gamma_{3}=1, \gamma_{2}=2 \\
\mu_{1}=\mu_{2}=\mu_{3}=0\end{array}$ & it & 1.0 & 1.0 & .98 & .04 & .99 & .99 & .23 & .01 & .69 & .02 & .01 & .93 & .61 & .01 & .38 & .92 & .93 \\
\hline 1) & $\begin{array}{l}\gamma_{1}=1, \gamma_{2}=1.5, \gamma_{3}=2 \\
\mu_{1}=\mu_{2}=\mu_{3}=0\end{array}$ & 1.0 & 1.0 & 1.0 & .14 & .02 & 1.0 & $.9 !)$ & 00 & .85 & .13 & .01 & .85 & .13 & .24 & .76 & .00 & .68 & 68 \\
\hline III) & $\begin{array}{l}\eta_{1}=1, \gamma_{2}=2, \gamma_{3}=3 \\
\mu_{1}=\mu_{2}=\mu_{3}=0\end{array}$ & 1.0 & 1.0 & 1.0 & .97 & .05 & 1.0 & 1.0 & .00 & .03 & .88 & .00 & .112 & .94 & .00 & .36 & .64 & .92 & .92 \\
\hline 1) & $\begin{array}{l}\gamma_{1}:=1, \gamma_{2}=5, \gamma_{1}=-.5 \\
\mu_{1}=\mu_{2}=\mu_{3}=0\end{array}$ & 1.0 & 1.0 & 1.1) & .41 & .04 & 1.0 & 1.0 & .010 & $.5 !)$ & .39 & .0010 & .77 & 11) & .00 & . & .02 & .72 & .37 \\
\hline
\end{tabular}


Table 4: Power of the tests and break selection when $m=2$ (cont'd)

\begin{tabular}{|c|c|c|c|c|c|c|c|c|c|c|c|c|c|c|c|c|c|c|c|c|c|}
\hline & \multirow[b]{3}{*}{ Caks: } & \multirow[b]{3}{*}{ Values } & \multirow[b]{3}{*}{ Specifications' } & \multicolumn{7}{|c|}{ Tests (probsaloility of rejoction) } & \multicolumn{9}{|c|}{ Probuhility of solorting $k$ hroiks } & \multicolumn{2}{|c|}{ Coverage } \\
\hline & & & & \multicolumn{3}{|c|}{ silp $F(k)$} & \multicolumn{2}{|c|}{ sup $F\left(t^{\prime}+1 \mid f^{\prime}\right)$} & \multicolumn{2}{|c|}{$\bar{D} \operatorname{milx}$} & \multicolumn{3}{|c|}{ Sinqulai } & \multicolumn{3}{|c|}{$B / C^{\circ}-\cdots$} & \multicolumn{3}{|c|}{1.112} & \multirow{2}{*}{$\begin{array}{l}\text { Rate } \\
\text { if } 1\end{array}$} & \multirow{2}{*}{$\begin{array}{l}95 \% \\
\text { 涪2 }\end{array}$} \\
\hline & & & & 1 & 2 & 3 & 211 & $3 \mid 2$ & II & H & () & I- & 2 & 11 & 1 & $\because$ & (1) & 1 & $\because$ & & \\
\hline i) & $\begin{array}{l}1 \\
E=.05 \\
T=120\end{array}$ & $\begin{array}{l}\gamma_{1}=1, \gamma_{2}=.5 \cdot \gamma_{3}=1 \\
\mu_{1}=11_{3}=0 ., 1 \cdot 2=.5\end{array}$ & $\because o r_{-} \prime \prime=0$ & .12 & .21 & .2 .1 & .185 & .111 & 17 & .25 & .58 & 111 & .02 & $\therefore$ & .106 & $.11: 3$ & 1.11 & .111 & .1) 0 & .46 & 46 \\
\hline b) & $\begin{array}{l}1 \\
E=0.05 \\
T=2 \cdot 10\end{array}$ & $\begin{array}{l}\gamma_{1}=1, \gamma_{2}=1.5, \gamma_{3}=2 \\
\mu_{1}=0, \mu_{3}=1, \mu_{2}=2\end{array}$ & $c o r_{-} u=0$ & 1.0 & $1.1)$ & $1.1)$ & 1.0 &.$(1) \overline{1}$ & 1.0 & 1.0 & .00 & .00 & .89 & .00 & .111 & $.9 \overline{1}$ & .011 & .12 & .88 & .95 & .95 \\
\hline (:) & $\begin{array}{l}l \\
\varepsilon=.05 \\
T=120\end{array}$ & $\begin{array}{l}\gamma_{1}=1, \gamma_{2}=2, \gamma_{3}=1 \\
\mu_{1}=0, \mu_{2}=1, \mu_{3}=2\end{array}$ & $c o r r_{-} n=0$ & 1.0 & 1.0 & 1.11 & .82 & .01 & 1.11 & 1.0 & .010 & .19 & .78 & .00 & .17 & $.7 !$ & .1111 & .72 & SS & ji & .85 \\
\hline (d) & $\begin{array}{l}2 \\
\varepsilon=.20 \\
T=120\end{array}$ & $\mu_{1}=\mu_{3}=0, \mu_{2}=.5$ & ror $n=1$ & .14 & .28 & .25 & $.09)$ & .00 & .23 & .28 & .86 & 13 & $.1) 1$ & $.39)$ & .21 & .37 & .79 & .12 & $.0 S$ & .96 & .95 \\
\hline e) & $\begin{array}{l}2 \\
\varepsilon=.20 \\
T=240\end{array}$ & $\mu_{1}=\mu_{3}=0, \mu_{2}=.5$ & $c o r_{-} u=1$ & .18 & .32 & .29 & .11 & (1) & .26 & .31 & .82 & .15 & $0: 3$ & .32 & $\therefore 0$ & .46 & .82 & .11 & ז'D. & .96 & .95 \\
\hline f) & $\begin{array}{l}2 \\
\varepsilon=.20 \\
T=120\end{array}$ & $\mu_{1}=\mu_{3}=0, \mu_{2}=1$ & $r o r_{-} u=1$ & .25 & .58 & .53 & .29 & .00 & .48 & .55 & .75 & .15 & .099 & .13 & .12 & .73 & .51 & 12 & .36 & .94 & .94 \\
\hline n) & $\begin{array}{l}2 \\
\varepsilon=.20 \\
T=2.10\end{array}$ & $\mu_{1}=\mu_{3}=0, \mu_{2}=1$ & $\operatorname{cor}_{-} u=1$ & .43 & .83 & .74 & $.5 \bar{j}$ & .00 & .71 & .78 & .57 & $.16 j$ & .26 & .033 & .04 & .90 & .33 & .11 & .56 & .93 & .93 \\
\hline h) & $\begin{array}{l}2 \\
\varepsilon=.20 \\
T=120\end{array}$ & $\mu_{1}=\mu_{3}=0, \mu_{2}=2$ & $\operatorname{cor}_{-} u=1$ & .47 & .97 & .94 & .86 & .00 & .94 & .96 & .53 & .06 & .41 & .100 & .10() & .95 & $0: 2$ & .111 & .96 & .93 & .93 \\
\hline i) & $\begin{array}{l}2 \\
\varepsilon=.20 \\
T=240\end{array}$ & $\mu_{1}=\mu_{3}=0, \mu_{2}=2$ & $\operatorname{cor}_{-} u=1$ & .91 & 1.0 & 1.0 & 1.0 & .0() & 1.0 & 1.0 & .09 & .00 & .90 & .00 & .00 & דיפ. & .00 & .00 & 1.0 & $.9 \overline{5}$ & .94 \\
\hline j) & $\begin{array}{l}2 \\
\varepsilon=.20 \\
T=120\end{array}$ & $\mu_{1}=\mu_{3}=0, \mu_{2}=4$ & $\operatorname{cor}_{-} u=1$ & .37 & 1.0 & 1.0 & 1.0 & .00 & 1.0 & 1.0 & .63 & .00 & $.3 T$ & $.00)$ & .00 & 1.0 & .00 & .00 & 1.0 & .99 & .99 \\
\hline k) & $\begin{array}{l}2 \\
E=20 \\
T=240\end{array}$ & $\mu_{1}=\mu_{3}=0, \mu_{2}=4$ & $\operatorname{cor}_{-} u=1$ & .96 & 1.0 & 1.0 & 1.0 & (1)0 & 1.0 & 1.0 & .0 .1 & .00 & .96 & .00 & .00 & 1.0 & .00 & .00 & 1.0 & .99 & .99 \\
\hline
\end{tabular}

Note: 1 In all cases het $u=0$. When constructing the tests, het_z $=1$ and when constructing the contidence intervals het $z=0$ ). 
Table 5.a: Power of the test.s and break selection when $m=2$.

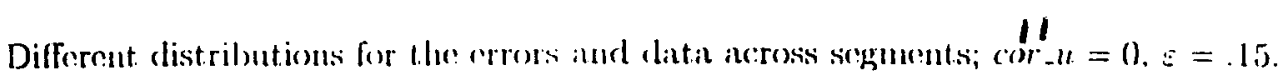

Cinse 1 with $\gamma_{1}=1, \gamma_{2}=1.5, \gamma_{3}=.5$ and $\mu_{1}=0, \mu_{2}=.5, \mu_{3}=-.5$.

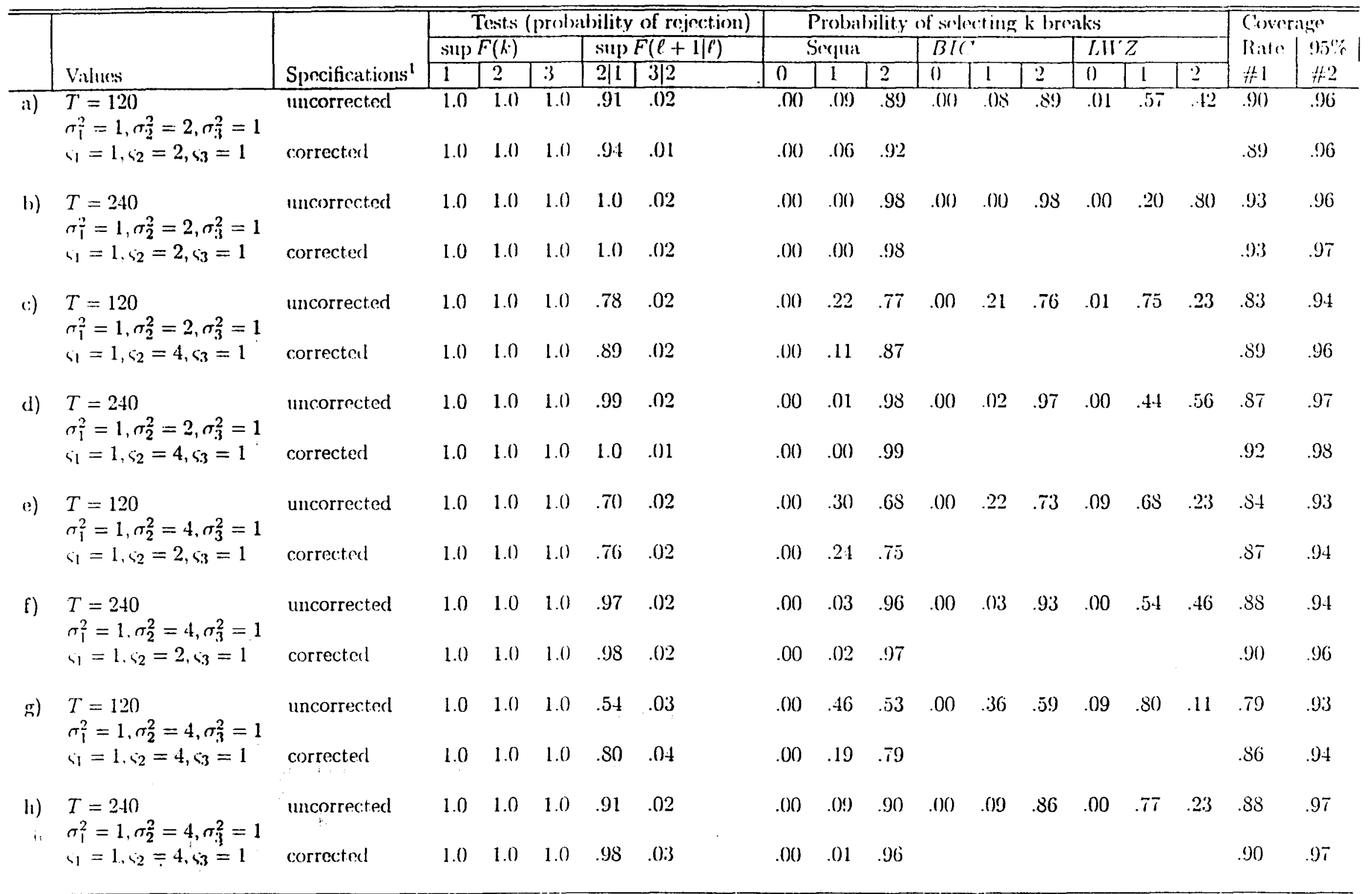

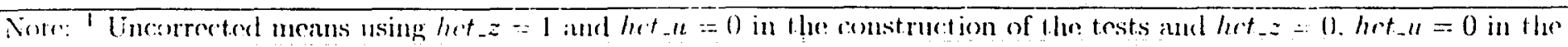

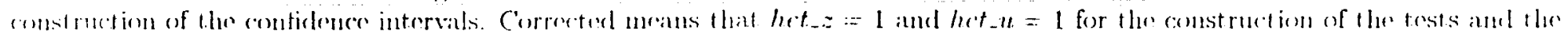

conficlones intervals. 
- Table 5.1): Power of the tests and break selection when $m=2$.

Different distributions for the croms and datia acrosis segments; corr- $_{-1}^{\prime}=0, \varepsilon=.20$.

Case 1 with $\gamma_{1}=1, \gamma_{2}=1.5, \gamma_{3}=2$ and $\mu_{1}=0, \mu_{2}=.5, \mu_{3}=1$

\begin{tabular}{|c|c|c|c|c|c|c|c|c|c|c|c|c|c|c|c|c|c|c|}
\hline & \multirow[b]{3}{*}{ Villues } & \multirow[b]{3}{*}{ Specifications ${ }^{1}$} & \multicolumn{5}{|c|}{ Tests (probaliblity of rejection) } & \multicolumn{9}{|c|}{ Probability of selecting $k$ broaks } & \multicolumn{2}{|c|}{ Coveraghe } \\
\hline & & & \multicolumn{3}{|c|}{$\operatorname{sil}) F(k)$} & \multicolumn{2}{|c|}{$\operatorname{stup} F\left(\ell+1 \mid \ell^{\prime}\right)$} & \multicolumn{3}{|c|}{ Serpua } & \multicolumn{3}{|c|}{$B I C$} & \multicolumn{3}{|c|}{ LIVZ } & \multirow{2}{*}{$\begin{array}{l}\text { Rate } \\
\# 1\end{array}$} & \multirow{2}{*}{$\begin{array}{l}95 \% \\
\# 2\end{array}$} \\
\hline & & & 1 & 2 & 3 & $2 / 1$ & $3 \mid 2$ & () & $i$ & 2 & 11 & 1 & 2 & 0 & l & $\underline{2}$ & & \\
\hline \multirow[t]{2}{*}{ a) } & $T=120$ & Uncorrected & 1.0 & 1.0 & 1.0 & .73 & .00 & .00 & .27 & $.7: 3$ & .00 & .28 & .72 & .01 & .91 & $.0 ! 9$ & .92 & .91 \\
\hline & $s_{1}=1, \varsigma_{2}=2, \varsigma_{3}=1$ & Corrected & 1.0 & 1.0 & 1.0 & .78 & .00 & .00 & .22 & .77 & & & & & & & .91 & .90 \\
\hline \multirow[t]{2}{*}{ b) } & $\begin{array}{l}T=240 \\
\sigma_{2}^{2}=1 \sigma_{2}^{2}=2, \sigma_{2}^{2}=1\end{array}$ & Uncorrected & 1.0 & 1.0 & 1.0 & 1.0 & .00 & .00 & .01 & .98 & .00 & $.0 !$ & .99 & .00 & .46 & .54 & .94 & .94 \\
\hline & $s_{1}=1, \varsigma_{2}=2, \varsigma_{3}=1$ & Corrected & 1.0 & 1.0 & 1.1) & 1.0 & .00 & .00 & .00 & .98 & & & & & & & .94 & .94 \\
\hline \multirow[t]{2}{*}{ c) } & $\begin{array}{l}T=120 \\
\sigma^{2}-1 \sigma^{2}=2 \sigma^{2}-1\end{array}$ & Uncorrected & 1.0 & 1.0 & 1.0 & .63 & .00 & .00 & .37 & .63 & .00 & .39 & .61 & .00 & .95 & .05 & .83 & .85 \\
\hline & $\varsigma_{1}=1, \varsigma_{2}=4, \varsigma_{3}=1$ & Corrected & 1.0 & 1.0 & 1.0 & .79 & .00 & .00 & .21 & .79 & & & & & & & .90 & .91 \\
\hline \multirow[t]{2}{*}{ d) } & $\begin{array}{l}T=240 \\
\sigma_{1}^{2}=1, \sigma_{2}^{2}=2, \sigma_{3}^{2}=1\end{array}$ & Uncorrected & 1.0 & 1.0 & 1.0 & .99 & .90 & .00 & .02 & .98 & .00 & .03 & .97 & .00 & .69 & .31 & .88 & .89 \\
\hline & $\varsigma_{1}=1, \varsigma_{2}=4, \varsigma_{3}=1$ & Corrected & 1.0 & 1.0 & 1.0 & .99 & .00 & .00 & .01 & .98 & & & & & & & .93 & .92 \\
\hline \multirow[t]{2}{*}{ e) } & $\begin{array}{l}T=120 \\
\sigma_{1}^{2}=1, \sigma_{2}^{2}=4, \sigma_{3}^{2}=1\end{array}$ & Uncorrected & 1.0 & 1.0 & 1.0 & .28 & .00 & .00 & .72 & .28 & .00 & .68 & .32 & .08 & .91 & .01 & .90 & .91 \\
\hline & $s_{1}=1, s_{2}=2, \varsigma_{3}=1$ & Corrected & 1.0 & 1.0 & 1.0 & .40 & .02 & .00 & .60 & .40 & & & & & & & .92 & .92 \\
\hline \multirow[t]{2}{*}{ f) } & $\begin{array}{l}T=240 \\
\sigma_{1}^{2}=1, \sigma_{2}^{2}=4, \sigma_{3}^{2}=1\end{array}$ & Uncorrected & 1.0 & 1.0 & 1.0 & .87 & .00 & .00 & .13 & .87 & .00 & .15 & .85 & .00 & .94 & .06 & .92 & .91 \\
\hline & $s_{1}=1, s_{2}=2, s_{3}=1$ & Corrected & 1.0 & 1.0 & $1 .(1)$ & .91 & .00 & .00 & .09 & .90 & & & & & & & .92 & .93 \\
\hline \multirow[t]{2}{*}{ g) } & $\begin{array}{l}T=120 \\
\sigma_{1}^{2}=1, \sigma_{3}^{2}=4, \sigma_{3}^{2}=1\end{array}$ & Uncorrected & 1.0 & 1.0 & 1.0 & .22 & .01 & .00 & .78 & .22 & .00 & .71 & .28 & .06 & .93 & .01 & .84 & .84 \\
\hline & $\varsigma_{1}=1, \varsigma_{2}=4 .{ }^{2}=1$ & Corrected & 1.0 & 1.0 & 1.0 & .60 & .02 & .00 & .40 & .60 & & & & & & & .90 & .90 \\
\hline \multirow{2}{*}{$\begin{array}{l}\text { h) } \\
h\end{array}$} & $\begin{array}{l}T=240 \\
\sigma^{2}-1 \sigma^{2}=4 \sigma_{2}^{2}=1\end{array}$ & Uncorrected & 1.0 & 1.0 & 1.0 & .82 & .00 & .00 & .18 & .81 & .00 & .23 & .77 & .00 & .97 & .03 & .88 & .89 \\
\hline & $\varsigma_{1}=1, s_{2}=4, c_{3}=1$ & Corrected & 1.0 & 1.0 & 1.0 & .98 & .01 & .00 & .02 & .96 & & & & & & & .91 & .91 \\
\hline
\end{tabular}

Note: ' Lencorrected means using het $z=1$ and het $u=0$ in the construction of the tests and het $z=0$. het $n=0$ in the coustruction of the confidenes intervals. Corrected mans that het $z=1$ and het $n=1$ for the construetion of the tests and the conficlence intervals. 
FUNDAÇÃO GETULIO VARGAS

BIBLIOTECA

ESTE VOLUME DEVE SER DEVOLVIDO A BIBLIOTECA

VA ÚLTIMA DATA MARCADA

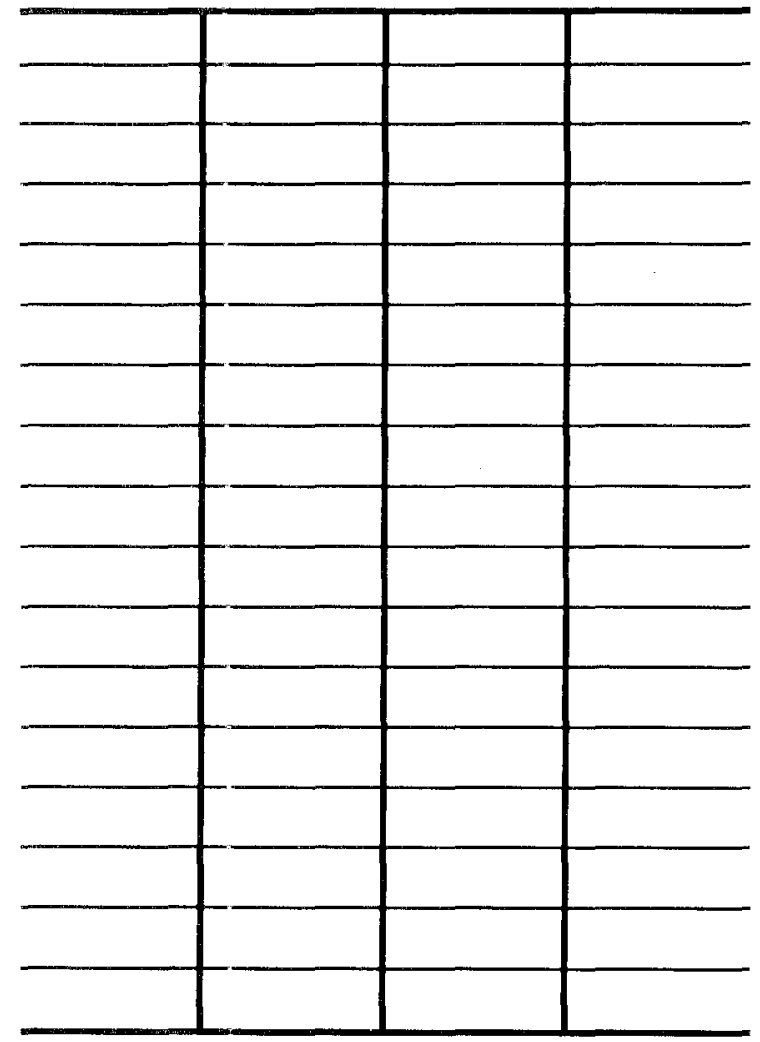

N.Cham. P/EPGE SPE B152m

Autor: Bai, Jushan

Título: Multiple structural change models : a simulation

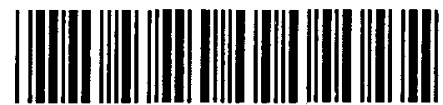

315922

90625

FGV - BMHS

No Pat.:315922/03 